\title{
Social Skills Deficits in Autism Spectrum Disorder: Potential Biological Origins and Progress in Developing Therapeutic Agents
}

\author{
Richard E. Frye ${ }^{1,2}$ (D) \\ Published online: 14 August 2018 \\ (C) The Author(s) 2018
}

\begin{abstract}
Autism spectrum disorder is defined by two core symptoms: a deficit in social communication and the presence of repetitive behaviors and/or restricted interests. Currently, there is no US Food and Drug Administration-approved drug for these core symptoms. This article reviews the biological origins of the social function deficit associated with autism spectrum disorder and the drug therapies with the potential to treat this deficit. A review of the history of autism demonstrates that a deficit in social interaction has been the defining feature of the concept of autism from its conception. Abnormalities identified in early social skill development and an overview of the pathophysiology abnormalities associated with autism spectrum disorder are discussed as are the abnormalities in brain circuits associated with the social function deficit. Previous and ongoing clinical trials examining agents that have the potential to improve social deficits associated with autism spectrum disorder are discussed in detail. This discussion reveals that agents such as oxytocin and propranolol are particularly promising and undergoing active investigation, while other agents such as vasopressin agonists and antagonists are being activity investigated but have limited published evidence at this time. In addition, agents such as bumetanide and manipulation of the enteric microbiome using microbiota transfer therapy appear to have promising effects on core autism spectrum disorder symptoms including social function. Other pertinent issues associated with developing treatments in autism spectrum disorder, such as disease heterogeneity, high placebo response rates, trial design, and the most appropriate way of assessing effects on social skills (outcome measures), are also discussed.
\end{abstract}

\section{Key Points}

Currently, there is no US Food and Drug Administrationapproved drug for the core symptoms of autism spectrum disorder.

Oxytocin, propranolol, and vasopressin agonists and antagonists are particularly promising agents for treating social function defects for individuals with autism, which are currently undergoing clinical investigations.

Bumetanide and microbiota transfer therapy have promising effects on core autism symptoms including social function.

Richard E. Frye

rfrye@phoenixchildrens.com

1 Division of Neurodevelopmental Disorders, Department of Neurology, Barrow Neurological Institute, Phoenix Children’s Hospital, 1919 E Thomas St, Phoenix, AZ 85016, USA

2 Department of Child Health, University of Arizona College of Medicine - Phoenix, Phoenix, AZ 85004, USA

\section{Introduction}

Autism spectrum disorder (ASD) is a behaviorally defined neurodevelopmental disorder now affecting almost $2 \%$ of children in USA [1]. Although ASD is a very heterogeneous disorder with many associated psychiatric and medical co-morbidities, specific core symptoms define its diagnosis. ASD is defined by a deficit in social communication along with the presence of repetitive and/or restricted interests and/or behaviors. Until recently, the deficits in social function and communication were considered two separate core symptoms. One consistency in the definition of autism as it has evolved over the past century is that a deficit in social function has always been included in defining autism.

This article reviews the history of autism, the development of social skills in typically developing (TD) children and how they develop abnormally in autism, the general pathophysiology of autism, outcome measures used to assess social function, and unique challenges in studying autism. Promising therapies that may address social deficits as well as the biological mechanisms that they target are discussed in detail. Overall, this article provides insights into 
the promising therapies for treating abnormalities in social function in individuals with ASD as well as the challenges faced in this area of research.

\section{Evolution of the Diagnosis of Autism Spectrum Disorder}

Bleuler introduced the term 'autism' in 1911 to describe adults with schizophrenia. Some believed that the term 'autism' was derived from the Freudian term 'autoerotism', a term used to describe a self-soothing, very immature preinfantile stage of hallucinatory thinking that preceded engagement with external reality [2]. Other accounts suggested that it originated from the Latin 'Autismus', which is derived from the Greek 'autos' meaning self, thus describing conditions where patients are morbidly self-absorbed. Piaget first applied the term to children to describe a pre-verbal stage of infant development [3]. Through the first half of the twentieth century, psychologists and psychiatrists in Britain and USA recognized a type of schizophrenia of childhood that is believed to be similar to what we know as autism today [2].

In the 1940s, two practitioners independently first used the term autism to describe a syndrome of childhood psychopathology. In 1943, Leo Kanner used the word autism to describe a unique syndrome in a series of children with obsessiveness, stereotypy, echolalia, and almost a complete lack of interaction with people [4]. In parallel, Hans Asperger, a Viennese child psychologist, described a disorder characterized by a lack of empathy, little ability to form friendships, one-sided conversation, intense absorption in a special interest, and clumsy movements [5]. This syndrome was later known as Asperger's syndrome (AS).

Psychiatry considered autism to be part of childhood schizophrenia until 1980 when it was described as its own entity in the Diagnostic Statistical Manual of Mental Disorders, 3rd Edition (DSM-III). In 1987, the DSM-III-Revised introduced the category of Pervasive Developmental Disorder, Not Otherwise Specified to capture children who did not meet the full criteria for autism and, in 1994, the DSMIV first officially recognized AS [6]. AS was defined in the DSM-IV as having a deficit in social function along with repetitive and/or restrictive interests and/or behaviors but without early language impairment.

The most recent version of the DSM (DSM-V) has come full circle, dropping the subcategories of Pervasive Developmental Disorder, Not Otherwise Specified, AS, and autistic disorder, now describing autism as a true spectrum depending on levels of impairment. Previous to the DSM-V, autism was diagnosed by impairment of both social interactions and communication along with the presence of repetitive movements and/or restrictive interests. Currently, the DSM-V posits that social interactions and communication are so inter-related that they are hard to separate. Thus, the DSM-V has combined these two impairments to define one of the core impairments as one significant abnormality in social communication. The DSM-V now only recognizes ASD as a diagnosis. Thus, ASD will be used throughout the remainder of the article.

\section{Social Development and Autism Spectrum Disorder}

The study of children who develop ASD has informed our knowledge of early social development. Early social behavior has been studied by reviewing videotapes of first birthday parties of children eventually diagnosed with ASD. Osterling and Dawson [7] demonstrated that children eventually diagnosed with ASD demonstrated significant fewer pointing and showing behaviors and less looking at people and orienting to their name as compared with TD peers. Likewise, Osterling et al. [8] found that children diagnosed with ASD or intellectual disability used fewer gestures and showed more repetitive motor movements than TD peers but only children with ASD looked at people and oriented to their name less than TD peers. Other studies have used retrospective questionnaires to investigate specific deficits in children that develop ASD as compared to TD peers or those who proceed to have developmental delays but not ASD [9, 10] (see Table 1).

One of the most consistent social deficits in children who develop ASD is a lack of non-verbal social gestures such as pointing, showing, and giving. Pointing starts to develop around 8 months of age and should make up the majority of gestures by 12 months of age [11]. Two types of pointing develop during childhood. Protoimperative pointing, a gesture that indicates what a child wants, is developmentally absent in young children with ASD although it sometimes develops in older children with ASD. Protodeclarative pointing is a joint attention gesture that is used to share experiences. Other important protodeclarative gestures that develop in early childhood include 'showing' and 'giving.' In 'showing' gestures, a child brings an object of interest

Table 1 Early developmental deficits in children diagnosed with autism as compared with typically developing children and children with other neurodevelopmental disorders

\begin{tabular}{ll}
\hline Imitation & Eye contact \\
Pointing at objects & Orienting to name \\
Playing 'peek-a-boo' & Joint attention \\
Seeking and enjoying cuddling & Responding to name \\
Checking for parents & Following someone's point \\
Interest in other children & Social smiling \\
Waving bye-bye without prompting & Demanding attention \\
\hline
\end{tabular}


to someone and extends their arms out holding the object toward a person's face to share their interest. In 'giving' gestures, a child places an object in someone's hand to share the object of interest with the person. These protodeclarative gestures are characteristically absent in ASD.

Quantitative measures of early behavior have concentrated on visual attention. In one of the first reports, children later diagnosed with ASD demonstrated different patterns of visual attention to point-light animation that simulated human movements at 15 months of age as compared to TD children [12]. Eye movement studies then demonstrated that children that went on to develop ASD looked at the mouth rather than the eyes at 15 months of age when looking at faces [13]. More recently, Jones and Klin [14] demonstrated that children later diagnosed with ASD lose the normal preference of attendance to the eyes when looking at faces in the first year of life.

The social skills deficits in individuals with high-functioning ASD (HFASD) have been attributed to deficits in several cognitive components, including the theory of mind and pragmatic competence [15], cognitive processing speed $[16,17]$, and metacognitive processes such as initiation and planning [18]. Deficits identified in AS provide some insight into the subtleties of the cognitive deficits in social function [19]. For example, although language is not overtly abnormal in AS, particular components of language competence may be deficient. Individuals with AS have adequate vocabulary and grammar skill but poor inference and comprehension of narrative. Although those with AS are thought to have a poor sense of humor, they actually have a deficit in gelotophilia (i.e., laughing at themselves) but show intact katagelasticism (i.e., laughing at others).

Despite research defining the basic cognitive deficits that underlie ASD, it is important to remember that the key neurophysiological deficit is probably at a cellular level, suggesting a systems-level dysfunction of the nervous system rather than a specific neural pathway or region of the brain that is affected. Thus, the systems-level dysfunction in neural systems may express itself in a slightly different manner depending on other intrinsic and extrinsic factors, leading to the heterogeneity that we find in the ASD population.

\section{General Pathophysiology of Autism}

\subsection{Neuropathological Abnormalities}

Abnormalities have been reported in almost every brain region, from the lower brainstem to the cortex, in individuals with ASD. First reported were abnormalities in the cerebellum and brain stem, including changes in cerebellar volume [20,21], vermis agenesis [22], and loss of Purkinje and granule cells and changes in the inferior olive [23].
Reductions in neuronal size and neuronal density are found in the limbic system [23, 24], particularly in CA1 and CA4, and hippocampal dendritic branching is reduced [25]. The trajectory of amygdala growth is unique in ASD with atypical age-dependent changes in dendritic spine density leading to amygdala dysfunction [26].

Brain growth in some individuals with ASD appears accelerated during the first years of life [20] followed by being prematurely diminished by early childhood [27, 28]. The early acceleration in head circumference is linked to increased brain volume [29, 30], non-neural tissue [31], and extra-axial fluid [32]. Increased white [21, 29] and gray [20, 21] matter volume has been reported in ASD. Increased white matter volume has been attributed to more short association fibers in the frontal and temporal lobes [33]. This is proposed to cause an imbalance between local and distant cortical communication and change the whole brain network architecture [34], leading to a deficit in large-scale cortical integration that is required for language, behavioral regulation, and social interactions. Other gray matter cortical abnormalities such as smaller, more compact, and numerous cortical minicolumns, particularly in the frontotemporal areas [35, 36] are reported in ASD. This is associated with a reduction in peripheral neuropil space [37], a space that contains gamma aminobutyric acid (GABA) inhibitory interneurons [36-42].

The association of tics and repetitive movement and response to anti-psychotic medications implicate basal ganglia circuits in ASD. The basal ganglia is also essential in eye movement, coordination, sensory modulation, and inhibition control, all neurological functions that are impaired in ASD [43]. Interestingly, the cerebellum, another structure implicated in ASD, and basal ganglia are connected through a short disynaptic pathway, highlighting their functional codependence [43]. The cerebellum is recognized for its role in cognition and affect, given the rich connection with the cerebral cortex [44].

\subsection{Neurotransmitter Abnormalities}

Autism spectrum disorder is associated with multiple neurotransmitter abnormalities, most notably abnormalities in monoamine (i.e., dopamine, norepinephrine, serotonin) [45-47] and amino acid (i.e., glutamate, GABA) [48-50] neurotransmitters. Excitation-to-inhibition imbalance [51] is believed to result in cortical hyperexcitability, which is associated with such ASD symptomatology as auditory-tactile hypersensitivity and seizures, in some cases [52], and abnormal gamma oscillations [53]. Several medications that target GABA (inhibitory) and glutamate (excitatory) neurotransmission have been developed using the Fragile $\mathrm{X}$ mouse model of ASD [54, 55].

$\mathrm{GABA}_{\mathrm{A}}$ neurotransmitters can be either excitatory or inhibitory, depending on the intracellular chloride level, 
which is regulated by the balance between the cation-chloride importer NKCC1 and exporter KCC2 [50]. Normally, early in life, KCC2 expression significantly increases, thereby decreasing intracellular chloride, causing $\mathrm{GABA}_{\mathrm{A}}$ channels to be inhibitory by hyperpolarizing neurons. It is believed that some children with ASD have a failure in this developmental change in $\mathrm{KCC} 2$ expression resulting in $\mathrm{GABA}_{\mathrm{A}}$ remaining excitatory [56].

There are multiple etiologies for neurotransmitter abnormalities including genetic mutations $[55,57]$ and metabolic disturbances. Abnormalities in redox metabolism found in the brain of children with ASD $[58,59]$ can disrupt glutamate metabolism $[60,61]$ and metabolic disorders associated with ASD, such as succinic semialdehyde dehydrogenase deficiency [62] and mitochondrial disorders [63], can influence GABAergic neurotransmission [64]. Monoamine neurotransmitter production can be disrupted by known metabolic abnormalities associated with disturbances in folate $[65,66]$ or tetrahydrobiopterin [45-47] metabolism. One neurotransmitter that is becoming increasing recognized to have a role in ASD, particularly in social impairment, is oxytocin [67]. Oxytocin is being found to modulate the activity of key brain regions associated with social cognition during socially relevant tasks [68].

\subsection{Metabolic Disorders}

Several metabolic disorders associated with ASD have associated treatments [65]. Folate is essential for many critical metabolic processes, including redox metabolism and methylation [69] and ASD is associated with polymorphisms in folate-related genes [70-81] and impaired folate transport across the blood-brain barrier as a result of folate receptor- $\alpha$ dysfunction [66, 82, 83]. Lower cobalamin levels have been reported in post-mortem ASD brain [84] and polymorphisms in cobalamin-associated genes [79] and enzymes [84] are associated with ASD. Tetrahydrobiopterin $\left(\mathrm{BH}_{4}\right)$ is critical for brain function, including the production of monoamine neurotransmitters, the breakdown of phenylalanine, and the production of nitric oxide [47]. The central (i.e., cerebrospinal fluid) level of $\mathrm{BH}_{4}$ is depressed in some individuals with ASD, particularly early in life [45, 47]. Carnitine deficiency may be common in ASD, based on adult reference ranges [85], and a defect in the gene that codes for the first enzyme in the carnitine biosynthesis pathway (TMLHE) is a risk factor for ASD [86]. In addition, some individuals with ASD have abnormal redox metabolism [59, 61, 71] and mitochondrial dysfunction [87]. It should be noted that metabolic systems are very interconnected and influenced by multiple factors, making the evaluation, treatment, and significance of metabolic disturbance very heterogeneous and complex.

\subsection{Immune Abnormalities}

ASD is associated with autoantibodies to neural tissue, including neuron-axon filament proteins, cerebellar neurofilaments, myelin basic protein, caudate, and serotonin receptors, just to name a few [88]. Recent studies implicate maternal antibodies that are believed to bind to and disrupt the development of the fetal brain prenatally [89]. Elevated cytokine levels in the cerebrospinal fluid and blood have been identified, particularly in cytokines associated with the innate immune system [90]. ASD has been associated with prenatal and postnatal infections, familial autoimmunity, and gastrointestinal inflammation, further suggesting a role for the immune system [88].

\subsection{Microbiome Imbalance}

There is a growing body of evidence that the trillions of microbes that inhabit the human digestive tract, known as the enteric microbiome, play a role in brain development and behavior [91]. The enteric microbiome may be atypical in ASD [92-97] with a decrease in diversity and an overrepresentation of disruptive species, including Clostridial species $[98,99]$. Microbiome disruption may be associated with children who have gastrointestinal symptoms at the time of, or prior to, the onset of ASD symptoms and in those with regressive-type ASD [100, 101]. An intriguing mouse model showed that altering the enteric microbiome using a probiotic ameliorated ASD-like behaviors [102]. Because most microbiome studies are correlational, atypical diet, altered metabolic and immune function, stress and/or inflammation could be driving microbiota alterations.

\section{Brain Circuits Specifically Involved in Social Interactions}

Social behavior involves a wide range of cognitive processes, including perception, attention, memory, motivation, and emotion [103]. The medial prefrontal cortex, temporoparietal junction, and posterior temporal sulcus are developmentally involved in the theory of mind skills while limbic structures including the amygdala, insula, and ventral striatum are intimately involved in emotional perception, expression, and regulation [104]. Structural and functional connectivity studies have found differences between TD individuals and individuals with ASD in these areas involved in social cognition [105]. Multiple studies have demonstrated changes in resting-state activity associated with ASD but heterogeneous methodology has prevented solid conclusions in this area of imaging research [106]. 


\section{Outcome Measures for Assessing Social Function}

A large majority of clinical trials use parent-reported outcomes. The Aberrant Behavior Checklist (ABC), a measure of disruptive behaviors, is most common, while trials focusing on social symptoms, commonly used the Social Responsiveness Scale (SRS). Despite some trials demonstrating a large placebo effect with the SRS [107], a metaanalysis of outcomes for the controlled group, social skills intervention trials found that the SRS demonstrated a large effect size [108]. Given the large heterogeneity in symptoms in children with ASD as well as the fact that some symptoms are more important to parents than other symptoms, an innovative approach is to individualize outcomes by rating targeted behaviors selected by parents [109].

Psychiatric studies widely use the clinician-rated Clinical Global Impression (CGI) scale. A scale based on the CGI that is specific for ASD, known as the Ohio Autism Clinical Impression Scale, has been developed and validated [110] and found to be reliable across cultures [111], yet it has only been used in a handful of studies [82, 112, 113]. Many clinical trials have measured change in ASD symptoms using the Childhood Autism Rating Scale (CARS) or the Autism Diagnostic Observation Schedule (ADOS), although these are instruments designed for diagnosis. The Calibrated Severity Score has been developed to measure change in ASD symptoms over time using the ADOS [114-116]. The Brief Observation of Social Communication Change has been developed to be more sensitive than the Calibrated Severity Score [117] and others have piloted alternative measures such as the General Social Outcome Measure [118].

Many studies use standard diagnostic instruments to measure changes in language, cognition, or intelligence. One of the issues with this approach is that they have a floor to the range in which they will measure ability. Because many individuals with ASD will be below the floor of the instrument, the instrument may not be sensitive to any change in ability as even the repeat measurement may be below the floor of the measurement range. In our recent clinical trial, we developed an algorithm to select the most abilityappropriate language test with an adequate dynamic range for optimally measuring change over time [82].

Beyond standard traditional outcome measures, investigators have utilized technology to develop more objective outcome measures. For example, actigraphy, which has been pioneered in monitoring sleep, has also been utilized to monitor behavior and activity level during the daytime [119]. Image analysis of movements with instruments such as the Kinect camera has been used to quantify repetitive movements [120]. Social visual stimuli such as faces with various emotions are used in conjunction with eye-tracking devices to monitor changes in visual attention [121]. Last, clinical trials are utilizing functional imaging in individuals with ASD to determine changes in activation and connectivity of key brain regions to validate treatment effectiveness.

Still, one must consider the face validity of the instruments used. Social function is a very complex cognitive construct with many components. Many outcome measures merely measure specific cognitive or behavioral components that may be necessary but not sufficient for successful social function. Some instruments represent very contrived social situations that may not represent real-world situations, particularly for the spontaneity and dynamics necessary for social competency. Clearly, better outcome measures using more natural social interactions need to be developed to better predict outcomes.

\section{Drug Treatments for Improving Social Interaction in Autism Spectrum Disorder}

The standard-of-care treatment for core ASD symptoms, particularly social interactions, is behavioral therapy such as applied behavioral analysis. However, such therapy requires full-time engagement with a one-on-one therapist over several years starting early in life $[122,123]$, is inconsistently covered by medical insurance, is not uniformly available in the education system [124, 125], typically results in incomplete recovery [122], and does not address the underlying pathophysiology of ASD. Indeed, despite standard-of-care behavioral therapy, optimal outcomes occur in only a minority of individuals with ASD and many individuals with ASD require life-long supportive care into adulthood [126]. Thus, safe and effective treatments that can augment available behavioral and educational interventions could accelerate achievement of optimal outcomes for a greater proportion of children with ASD.

Development of drug treatments for ASD uses several approaches. One approach targets neural pathways involved in social cognition by manipulating specific neurotransmitters, such as OT. The other targets brain-specific physiological abnormalities or non-brain systematic abnormalities to improve overall brain function. Table 2 outlines the controlled clinical trials discussed in this section that have at least one measure of social function. Secondary outcome measure(s) pertaining to social function are outlined if the primary outcome measure does not reflect a measure of social function. For outcomes that are significant, either the effect of the treatment and placebo are reported or the overall effect size. In some cases, neither was reported, thus the outcome is just noted as significantly different between the two groups. If there is no significant (NS) difference that is noted also noted. All the secondary measures used in the study are also listed. Table 3 outlines the significant adverse effects reported in controlled trials for the treatments discussed. 
Table 2 Summary of the results of controlled studies of promising pharmacological agents

\begin{tabular}{|c|c|c|c|c|c|}
\hline Study & Primary/social outcome & Treatment effect & Placebo effect & Effect size/sig & Secondary outcomes \\
\hline \multicolumn{6}{|l|}{ Risperidone } \\
\hline \multicolumn{6}{|l|}{ Scahill et al. [127] } \\
\hline Study 1 [128] & ABC-SW (2) & & & 0.42 & $\mathrm{ABC}$ \\
\hline Study 2 [129] & ABC-SW (2) & & & 0.65 & $\mathrm{ABC}$ \\
\hline \multirow[t]{2}{*}{ Naharaj et al. [130] } & CARS/CGAS (1) & & & Sig & GIR \\
\hline & $\begin{array}{l}\text { Social responsiveness item } \\
\text { of parent questionnaire (2) }\end{array}$ & & & Sig & \\
\hline \multicolumn{6}{|l|}{ Arbaclofen } \\
\hline Delahunty et al. [139] & ABC-SW (1) & & & NS & ABC, CGI-I, CGI-S, VABS \\
\hline \multicolumn{6}{|l|}{ Bumetanide } \\
\hline \multirow[t]{2}{*}{ Lemonnier et al. [140] } & CARS (1) & $-5.6 \pm 4.0$ & $-1.8 \pm 5.1$ & & CGI-TI, ADOS \\
\hline & ADOS: reciprocity (2) & & & NS & \\
\hline \multirow[t]{2}{*}{ Lemonnier et al. [141] } & CARS (1) & $\begin{array}{l}0.5 \mathrm{mg}:-5.0 \pm 4.3 \\
1.0 \mathrm{mg}:-3.1 \pm 3.3 \\
2.0 \mathrm{mg}:-3.2 \pm 4.0\end{array}$ & $-1.6 \pm 2.3$ & & SRS, CGI-I \\
\hline & SRS (2) & $\begin{array}{l}0.5 \mathrm{mg}:-12.4 \pm 23.6 \\
1.0 \mathrm{mg}:-13.2 \pm 20.5 \\
2.0 \mathrm{mg}:-21.8 \pm 19.8\end{array}$ & $-1.6 \pm 20.4$ & & \\
\hline \multicolumn{6}{|l|}{ Memantine } \\
\hline Ghaleiha et al. [148] & ABC-SW (2) & & & NS & $\mathrm{ABC}$ \\
\hline Aman et al. [107] & SRS (1) & & & NS & $\begin{array}{l}\text { CATS, CAASTS, CCC-2, } \\
\text { CGI, ABC }\end{array}$ \\
\hline \multicolumn{6}{|l|}{ Propanolol } \\
\hline Zamzow et al. [151] & GSOM (1) & & & 0.40 & SCAS, BAI, ECG, SC \\
\hline \multirow[t]{3}{*}{ Zamzow et al. [152] } & Facial scanning & & & & \\
\hline & Mouth (1) & & & 0.59 & $\mathrm{HR}, \mathrm{BP}$ \\
\hline & Eyes/nose (1) & & & NS & \\
\hline \multicolumn{6}{|l|}{ Oxytocin (single) } \\
\hline Hollander et al. [159] & $\begin{array}{l}\text { Affective speech Compre- } \\
\text { hension (1) }\end{array}$ & & & 0.66 & None \\
\hline Guastella et al. [160] & RMET (1) & $49 \pm 15 \%$ & $45 \pm 18 \%$ & & \\
\hline \multirow[t]{3}{*}{ Auyeung et al. [161] } & $\begin{array}{l}\text { Facial scanning (no. of fixa- } \\
\text { tions) }\end{array}$ & & & & \\
\hline & Eyes (1) & & & 0.86 & Total fixation time \\
\hline & Mouth/other (1) & & & NS & Subgroup analysis \\
\hline \multirow[t]{5}{*}{ Kanat et al. [162] } & $\begin{array}{l}\text { House-face dot-probe Para- } \\
\text { digm }(100 \mathrm{~ms} / 500 \mathrm{~ms})\end{array}$ & & & & Correlation with social anxiety \\
\hline & Reaction time (1) & & & NS & \\
\hline & Attentional bias (1) & & & NS & \\
\hline & Adherence (1) & & & NS & \\
\hline & Allocation $(500 \mathrm{~ms})(1)$ & & & Sig & \\
\hline \multicolumn{6}{|l|}{ Oxytocin (prolonged) } \\
\hline \multirow[t]{2}{*}{ Anagnostou et al. [163] } & RBS-R (1) & & & 0.64 & RMET, SRS, YBOCS, \\
\hline & DANVA/CGI (1) & & & NS & WHOQOL-E \\
\hline \multirow[t]{4}{*}{ Watanabe et al. [165] } & ADOS (1) & & & & \\
\hline & Reciprocity & $-8.8 \pm 15.2$ & $12.2 \pm 24.1$ & 0.78 & rsFC, AQ, SRS, RBS-R, STAI, \\
\hline & Communication/repetitive & & & NS & CESD, QOL, CGI-E, GAF \\
\hline & CARS (1) & & & NS & \\
\hline \multirow[t]{2}{*}{ Yatawara et al. [166] } & SRS (1) & $13.5 \pm 17.2$ & $5.2 \pm 17.3$ & & ADOS, DBC, CGI-I, CSQ \\
\hline & RBS-R (1) & & & NS & \\
\hline
\end{tabular}


Table 2 (continued)

\begin{tabular}{|c|c|c|c|c|c|}
\hline Study & Primary/social outcome & Treatment effect & Placebo effect & Effect size/sig & Secondary outcomes \\
\hline Dadds et al. [113] & Family interaction task (1) & & & NS & $\begin{array}{l}\text { Global ratings of social } \\
\text { interaction, SSRS, SRS- } \\
\text { AM, OACIS, CARS, FERT, } \\
\text { DISCAP-ASD }\end{array}$ \\
\hline Guastella et al. [167] & SRS/CGI-I (1) & & & NS & $\begin{array}{l}\text { DBC, RBS-R, RMET, } \\
\text { DANVA, Biological motion }\end{array}$ \\
\hline \multirow[t]{2}{*}{ Kosaka et al. [168] } & CGI-I overall (1) & & & NS & ABC, ZSRDS, STAI, TAS \\
\hline & ABC-SW (2) & & & NS & \\
\hline \multicolumn{6}{|l|}{ Vasopressin } \\
\hline \multirow[t]{3}{*}{ Umbricht et al. [185] } & Biological motion & & & & $\begin{array}{l}\text { ABC, ASR, CGI-I, RMET, } \\
\text { STAI, SCIT, OI }\end{array}$ \\
\hline & Orienting preference & & & 0.80 & \\
\hline & Composite & & & NS & \\
\hline Bolognani et al. [186] & SRS & & & NS & $\begin{array}{l}\text { VABS, ABC, RBS-R, CGI-I, } \\
\text { STAI, ADAMS }\end{array}$ \\
\hline \multicolumn{6}{|l|}{ Leucovorin calcium } \\
\hline \multirow[t]{3}{*}{ Frye et al. [82] } & Verbal communication (1) & & & 0.70 & VABS, ABC, OACIS, ASQ, \\
\hline & ABC-SW (2) & & & Sig & SRS, AIM \\
\hline & SRS (2) & & & NS & \\
\hline \multicolumn{6}{|l|}{ Cobalamin } \\
\hline \multirow[t]{4}{*}{ Hendren et al. [194] } & CGI-I (1) & & & 0.70 & $\mathrm{ABC}, \mathrm{SRS}$ \\
\hline & ABC-SW (2) & & & NS & \\
\hline & SRS social motivation (2) & & & 0.73 & \\
\hline & SRS other (2) & & & NS & \\
\hline \multicolumn{6}{|l|}{$N$-acetyl-L-cysteine } \\
\hline \multirow[t]{4}{*}{ Hardan et al. [196] } & ABC-I (1) & & & 0.96 & ABC, RBS-R, SRS, CGI-I \\
\hline & ABC-SW (2) & & & NS & \\
\hline & SRS social cognition (2) & & & 0.99 & \\
\hline & SRS other (2) & & & NS & \\
\hline \multirow[t]{2}{*}{ Ghanizadeh et al. [197] } & ABC-I (1) & & & 0.14 & $\mathrm{ABC}$ \\
\hline & ABC-SW (2) & & & NS & \\
\hline \multirow[t]{2}{*}{ Nikoo et al. [198] } & ABC-I (1) & $9.3 \pm 4.1$ & $5.4 \pm 3.2$ & & $\mathrm{ABC}$ \\
\hline & ABC-SW (2) & & & NS & \\
\hline Dean et al. [199] & SRS, CCC-2, RBS-R (1) & & & NS & DBC-P, PGI-I, CGI-I, CGI-S \\
\hline \multirow[t]{2}{*}{ Wink et al. [200] } & CGI-I (1) & & & NS & CGI-S, ABC, SRS, VABS \\
\hline & ABC-SW/SRS (2) & & & NS & \\
\hline \multicolumn{6}{|l|}{ Tetrahydrobiopterin } \\
\hline \multirow[t]{2}{*}{ Danfors et al. [201] } & CARS: overall & & & NS & $\begin{array}{l}\text { CARS: communication and } \\
\text { stereotyped behavior }\end{array}$ \\
\hline & CARS: social interactions & $1.6 \pm 1.1$ & $0.3 \pm 1.4$ & & \\
\hline \multirow[t]{4}{*}{ Klaiman et al. [202] } & CGI-I/CGI-S & & & NS & PLS, SRS, ABC, VABS \\
\hline & SRS social awareness & & & Sig & \\
\hline & SRS autism mannerism & & & Sig & \\
\hline & ABC-SW & & & NS & \\
\hline \multicolumn{6}{|l|}{ Carnitine } \\
\hline \multirow[t]{5}{*}{ Geier et al. [203] } & CARS & $1.9 \pm 2.5$ & $0.1 \pm 1.4$ & & \\
\hline & CGI & $-0.5 \pm 0.6$ & $0.1 \pm 0.7$ & & \\
\hline & ATEC total & & & NS & \\
\hline & ATEC sociability & & & NS & \\
\hline & Hand strength & & & NS & \\
\hline Fahmy et al. [204] & CARS & & & Sig & \\
\hline
\end{tabular}


Table 2 (continued)

\begin{tabular}{lllll}
\hline Study & Primary/social outcome & Treatment effect & Placebo effect Effect size/sig Secondary outcomes \\
\hline Sulforaphane & & & & None \\
Singh et al. [205] & ABC total & $21.4 \pm 4.5$ & $2.0 \pm 3.5$ & $2.0 \pm 3.5$ \\
& SRS total & $20.4 \pm 4.5$ & & $0 \%$ \\
& OACIS: improved & & $9 \%$ & \\
& Social & $46 \%$ & $0 \%$ & NS \\
& Aberrant behavior & $54 \%$ & & \\
& Verbal & $42 \%$ & & \\
& Other scales & & & \\
& & &
\end{tabular}

The primary outcome for all studies is given. If the primary outcome is not a measure of social function, then secondary outcomes that reflect social function are listed. The number in parenthesis after the outcome measures indicates whether it is a primary or secondary outcome measure. Studies that did not have any social outcome measures were not included in this table

$A B C$ Aberrant Behavior Checklist, $A B C$-I ABC-Irritability Subscale, $A B C$-SW ABC-Social Withdrawal Subscale, ADAMS Anxiety, Depression and Mood Scale, ADOS Autism Diagnostic Observation Schedule, AIM Autism Impact Measure, AQ Autism Spectrum Quotient, ASR affective speech recognition, $A S Q$ Autism Symptoms Questionnaire, ATEC Autism Treatment Evaluation Checklist, BAI Beck Anxiety Inventory, BP blood pressure, CAASTS Core and Associated Autism Symptom Treatment Scale, CARS Childhood Autism Rating Scale, CATS Core Autism Treatment Scale, CATS-I Core Autism Treatment Scale-Improvement, CCC-2 Children's Communication Checklist-2, CESD Centre for Epidemiologic Studies Depression Scale, CGAS Children's Global Assessment Scale, CGI Clinical Global Impression Scale, CGI-E CGIEfficacy, CGI-I CGI-Improvement, CGI-S CGI-Severity Scale, CGI-TI CGI-Therapeutic Index, CSQ Caregiver Strain Questionnaire, DANVA Diagnostic Analysis of Nonverbal Accuracy, $D B C$ Developmental Behavior Checklist, $D B C$-P Developmental Behavioural Checklist-Primary Caregiver Version, DISCAP-ASD Diagnostic Interview Schedule for Children, Adolescents, and Parents, ECG electrocardiography, FERT facial emotion recognition task, GAF Global Assessment of Functioning, GIR General Improvement Rating, GSOM Conversational Reciprocity task of the General Social Outcome Measure, HR heart rate, $N S$ no significant differences between treatment and placebo group, PGI-I Parent Global Impression-Improvement, $P L S$ Preschool Language Scales, $Q O L$ quality-of-life questionnaire, OACIS Ohio Autism Clinical Impression Scale, $O I$ olfactory identification, $R B S-R$ Repetitive Behaviour Scale-Revised, $R M E T$ Reading Mind in the Eyes Test, $r s F C$ resting-state functional connectivity, $S C$ skin conductance, SCAS Spence Children's Anxiety Scale, SCIT Scripted Communication and Interaction Test, Sig significant differences between treatment and placebo group, SRS Social Responsiveness Scale, SRS-AM Social Reciprocity Scale Autistic Mannerisms, SSRS Social Skills Rating Scale, STAI State and Trait Anxiety Inventory, TAS Toronto Alexithymia Scale, VABS Vineland Adaptive Behavior Scale, WHOQOL-E World Health Organization Quality of Life Questionnaire - emotional/social subscales, YBOCS Yale Brown Obsessive Compulsive Scale, ZSRDS Zung Self-Rating Depression Scale

\subsection{Pharmacological Agents}

\subsubsection{Antipsychotics}

The only US Food and Drug Administration (FDA)approved drugs for ASD are atypical antipsychotics, which are indicated for irritability, a serious behavioral problem associated with ASD. Repeated reports document improvements in disruptive behaviors with risperidone and aripiprazole, but other reports are mixed on whether these medications improve social function as a secondary benefit.

In 2013, Scahill et al. [127] performed a secondary analysis of two previously published, large risperidone clinical trials, one double-blind placebo-controlled (DBPC) $(n=101)$ [128] and one comparative efficacy trial examining risperidone treatment with and without parent training $(n=124)$ [129]. Significant improvement on the ABC-Social Withdrawal (ABC-SW) subscale was found with a medium effect size. In a medium-sized $(n=39)$ DBPC trial of risperidone, significant improvements in "social responsiveness" were reported for children taking risperidone on a parent questionnaire [130]. However, two uncontrolled follow-up studies demonstrated mixed effects of social symptoms with long-term risperidone treatment. In a 21-month follow-up study after a DBPC study, improvements in both ABC-SW $(n=83)$ and social skills on the Vineland Adaptive Behavior Scale (VABS) $(n=76)$ showed a positive relationship with risperidone exposure [131]. In contrast, in a 10-year longitudinal study, the 33 children who reportedly improved with risperidone, showed improvement in focus and aggression but no significant change on the SRS [132].

Although atypical antipsychotics are beneficial for some ASD symptoms, the detrimental effects on lipid and glucose metabolism and body weight [133-135], and the increased risk of cardiovascular disease and type 2 diabetes mellitus [136] and tardive dyskinesia [137] are concerning. Thus, alternative safe medications that affect target pathophysiological processes and treat core ASD symptoms are needed. 
Table 3 Adverse effects (AEs) reported in controlled studies of promising pharmacological agents

\begin{tabular}{ll}
\hline Treatment & Reported AEs \\
\hline Risperidone & Weight gain, appetite increase, fatigue, drowsiness, drooling, dizziness \\
Arbaclofen & No significant AEs \\
Bumetanide & Hypokalemia, diuresis, appetite loss, dehydration, asthenia \\
Memantine & Irritability, aggression \\
Propanolol & No significant AEs \\
Oxytocin (single-dose administration) & No significant AEs \\
Oxytocin (prolonged administration) & Thirst, urination, constipation \\
Vasopressin & Dizziness, attention disturbance, anxiety, infusion-site rash \\
Leucovorin calcium & No significant AEs \\
Cobalamin & No significant AEs \\
N-acetyl-L-cysteine & Drowsiness, fatigue, constipation, increased appetite, nervousness \\
Tetrahydrobiopterin & No significant AEs \\
Carnitine & No significant AEs \\
Sulforaphane & Weight gain \\
\hline
\end{tabular}

\subsubsection{GABAergic Modulation}

7.1.2.1 Arbaclofen Baclofen is a $\mathrm{GABA}_{\mathrm{B}}$ agonist used to treat spasticity. Because the $\mathrm{S}$-isomer is believed to account for adverse effects such as somnolence, STX-209 (i.e., Arbacofen), the active R-enantiomer was developed [55]. An 8-week open-label trial enrolled 32 children and adolescents with ASD and high irritability [138]. Improvement occurred in most outcomes measured, including the SRS. A follow-up 12-week DBPC trial of 150 children, adolescents, and young adults with ASD and reduced social function did not show improvements in the primary outcome measure, the ABCSW [139]. However, a per-protocol analysis demonstrated a significant improvement in the VABS Socialization subscale.

7.1.2.2 Bumetanide The diuretic bumetanide, a chlorideimporter antagonist, targets abnormalities in intracellular $\mathrm{GABA}_{\mathrm{A}}$ chloride levels [56]. In the first single-center trial, 60 children with ASD received $1 \mathrm{mg}$ of bumetanide daily for 3 months. Bumetanide improved scores on the CARS but the ADOS Reciprocity subscale did not improve [140]. In a large $(n=80)$, six-center 3-month DBPC with three doses $(0.5 \mathrm{mg}$, $1.0 \mathrm{mg}$, or $2.0 \mathrm{mg}$ twice daily), bumetanide improved scores on the CARS and SRS [141]. The treatment was well tolerated in these trials with some patients showing mild hypokalemia requiring potassium supplementation.

Two studies measured biomarkers of social cognition during open-label bumetanide treatment. Ten months of bumetanide treatment in adolescents and young adults $(n=7)$ improved emotion recognition and enhanced activation in social and emotional perception areas of the brain during the viewing of emotional faces [142]. In a study on the same population plus two additional participants $(n=9)$, bumetanide normalized amygdala activation during a constrained eye contact task and increased the time spent looking at the eyes in face stimuli [143].

\subsubsection{Glutamate Neurotransmission}

Memantine, an $N$-methyl-D-aspartate receptor antagonist, has been investigated for its ability to improve social function in both open-label and controlled studies [48]. Two small ( $n=30 ; n=18)$ open-label studies reported improvements in eye contract [144] and social withdrawal [145] in children with ASD. A large $(n=151)$ open-label study reported improved social behavior in children and young adults with ASD [146]. Memantine significantly improved SRS scores in a small $(n=18)$ 12-week open-label trial of adults with HFASD [147].

Two DBPC studies have examined the effect of memantine on social function. A medium-sized $(n=40)$ DBPC add-on to risperidone study of children with ASD reported improvements in ABC Irritability, Stereotypy, and Hyperactivity, but not Social Withdrawal, subscales [148]. In a large $(n=121)$ DBPC 12-week study, once-daily extended-release memantine did not significantly affect the SRS owing to a large improvement in the placebo group [107]. Thus, DBPC studies do not show improvement in social symptoms with memantine, although they do suggest an excellent safety profile.

\subsubsection{Propranolol}

Propranolol is a blocker of the beta-adrenergic receptor that acts both peripherally and centrally. Peripheral effects primarily target the autonomic nervous system where propranolol affects primarily heart rate and blood pressure. Central 
targets include the widespread norepinephrine circuits, including targets in the brainstem, cortex, and, notably, the amygdala.

Propranolol was first reported to improve social behaviors and speech in a small $(n=8)$, open-label, 4- to 19-month trial of adults with ASD [149]. A recent case study demonstrated that prolonged (several months) treatment with propranolol improves hypersexual behaviors in individuals with ASD [150].

Two small DBPC trials have examined the effects of single-dose propranolol on social function. In a DBPC $(n=20)$ crossover study, individuals with ASD demonstrated improved conversational reciprocity with a blinded researcher after a single dose of propranolol [151]. Simultaneous measures of autonomic activity and anxiety did not account for this effect. In another DBPC crossover study $(n=14)$, a single dose of propranolol decreased time spent looking at the mouth during face scanning in individuals with ASD as compared with TD controls [152]. Currently, the Thompson Center for Autism and Neurodevelopmental Disorder at the University of Missouri is conducting DBPC trials aimed at better understanding the effect of propranolol on social interaction in adults and adolescents with HFASD (NCT 02871349) and in young children with ASD combined with early intensive behavioral interventions (NCT 02428205).

Studies have examined the cognitive and behavioral benefits of propranolol as well as its effect on brain circuitry. Three controlled studies found that single-dose propranolol improves language. In a small $(n=20)$ DBPC crossover study of adults and adolescents with ASD, propranolol treatment improved the speed of solving verbal anagram problems with the improvement related to autonomic activity and anxiety [153]. Still, in another small $(n=14$ individuals with ASD, 14 control individuals) DPBC crossover study on adults and adolescents with HFASD, propranolol improved category fluency, but not letter fluency [154]. Another small DBPC study ( $n=14$ adults with HFASD, 13 TD controls) demonstrated that propranolol improves working memory but not inhibitory control on a continuous performance task [155].

The effect of propranolol on functional brain activity has been investigated in relation to the default mode resting-state network connectivity in ASD. The first study of this type ( $n=10$ adults with ASD) demonstrated that single-dose nadolol, a beta-antagonistic that does not cross the blood-brain barrier, did not influence functional connectivity like single-dose propranolol, thereby demonstrating that changes in brain function were not the result of peripheral changes in autonomic function [156]. In a more recent study of 15 adolescents and young adults with HFASD, single-dose propranolol modulated the default mode network by decreasing connectivity between the default mode resting-state network and the dorsal medial prefrontal cortex and increasing connectivity between the default mode resting-state network and medial temporal lobe [157].

\subsubsection{Oxytocin/Vasopressin Pathways}

7.1.5.1 Oxytocin Treatment with OT is one of the most active areas of drug treatment research in ASD. At least a dozen clinical trials have investigated the use of OT in ASD with over a dozen other registered trials currently underway. Clinical trials have been conducted in several ways: examining the effect of a one-time OT dose or examining the effect of prolonged OT treatment.

7.1.5.1.1 Single Oxytocin Dose Studies Many studies have examined the effect of an 'oxytocin challenge' by examining changes in specific measurements of social function resulting from a single dose of OT. In a small $(n=15)$ DBPC study of patients with ASD, intravenous OT reduced repetitive behaviors [158]. In a second small $(n=15)$ study of adults with ASD, intravenous OT improved the comprehension of affective speech [159].

The remainder of the 'oxytocin challenge' trials has used an intranasal (IN) OT spray. In a small $(n=16)$ DBPC crossover study of adolescents with ASD, 18 or 24 IU of OT improved performance on the Reading the Mind in the Eyes Task, particularly in those that were younger and received a lower dose [160]. In a medium-sized $(n=32$ individuals with ASD; 34 control individuals) DBPC crossover study, 24 IU enhanced gaze time to the eyes in a real-time interaction with a researcher, especially in those with the most impaired levels of eye contact at baseline [161]. In a medium sized ( $n=29$ individuals with ASD; 30 control individuals) DPBC crossover trial, $24 \mathrm{IU}$ increased the allocation of attention to faces, as compared to houses, in individuals with ASD for a 500-ms stimuli presentation but not the 100-ms stimuli presentation. Oxytocin also decreased the effect of baseline social anxiety on modulating attention to faces [162].

Thus, OT seems to improve the performance of individuals with ASD on social tasks, particularly those with high social dysfunction at baseline. However, most of these studies have been performed on adults with HFASD. In addition, the combination of the treatment with a specific task may represent a somewhat contrived social situation and does not explicitly translate to real-time situations where the need for social engagement is not necessarily planned. Thus, other studies have examined prolonged treatment with OT on ASD.

7.1.5.1.2 Prolonged Oxytocin Treatment In a small $(n=19)$ DBPC study, 24 IU of IN OT twice a day for 6 weeks improved the Repetitive Behaviour Scale-Revised but not the Diagnostic Analysis of Nonverbal Accuracy or the CGI 
in adults with ASD [163]. In another early study, eight adolescent male individuals with ASD underwent an open-label dose escalation from 8 IU to 24 IU, increasing the dose by 8 IU every 2 months. The majority showed improvements on the reciprocity scale of the ADOS [164]. These promising trials led to further controlled studies.

Several controlled studies demonstrated positive findings. In a small $(n=20)$ DBPC of male adults with HFASD, 6 weeks of OT significantly improved social reciprocity as measured by the ADOS [165]. In a medium-sized $(n=31)$ DBPC crossover trial, twice-daily (12 IU AM, 24 IU PM) OT for 5 weeks significantly improved SRS scores [166].

Other studies failed to find positive results. In a mediumsized $(n=38) 5$-day DPBC trial of young male individuals with ASD, 12 IU or 24 IU of IN OT administered during parent-child interaction training sessions did not improve emotion recognition, social interaction skills, or general behavioral adjustment [113]. In another medium-sized $(n=50)$ DBPC trial of adolescent male individuals, twice daily 18 IU or 24 IU of IN OT for 8 weeks did not improve SRS or CGI-I [167].

In perhaps the largest $(n=60)$ clinical trial on OT, young adults with HFASD received low-dose (16 IU) OT, highdose (32 IU) OT, or placebo during a 12-week DBPC trial. Although there was no overall improvement in the CGI-I, male individuals in the high-dose group demonstrated significant improvement in CGI-I as compared with placebo and OT receptor polymorphisms were related to improvement in the low-dose groups (see below) [168]. This study demonstrates the complexity of OT clinical trials and highlights the fact that subject characteristics, including genetic background, as well as OT dosage, may contribute to OT effectiveness.

7.1.5.1.3 Effect of Oxytocin on Neural Circuits In a small placebo-controlled crossover study of adults $(n=14$ individuals with ASD; $n=14$ control individuals), 24 IU of IN OT increased right amygdala activity to socially relevant facial stimuli in the individuals with ASD [169]. In a medium-sized $(n=40)$ DBPC crossover trial of male adults with HFASD, 24 IU of IN OT increased the activity and neuronal metabolism of and connectivity with the medial prefrontal cortex as well as improved the ability of the participants to use non-verbal information to make judgments about conflicting social information [170, 171]. In a small $(n=20)$ DBPC of male individuals with ASD, 24 IU of IN OT improved performance on the Sally-Anne Task, a well-known first-order false-belief task that measures the ability to infer another person's social emotions, and increased activity in the right anterior insula, an area found to be diminished in activity during this task in male individuals with ASD [172]. One small $(n=20)$ DBPC crossover clinic trial of prolonged (6 weeks) treatment with
OT resulted in an enhancement of task-independent restingstate functional connectivity between the anterior cingulate cortex and dorso-medial prefrontal cortex as well as taskdependent activity in these regions [165]. Thus, in several functional brain imaging studies, OT has been shown to enhance activity, connectivity, and metabolism of key brain regions involved in social cognition.

7.1.5.1.4 Predictors of Oxytocin Response Several studies have examined the effect of specific polymorphisms on the response to OT treatment. In one study of 56 healthy young men, the rs 3796863 polymorphism of the transmembrane protein involved in OT secretion (CD38 gene) modulated activation of the left fusiform gyrus during processing of visual social stimuli such that individuals with this polymorphism had more marked neural responses to OT [173]. In another study of 20 young adults with HFASD, the rs6791619 polymorphism of the OT receptor gene (OXTR) predicted improvement in male participants with ASD to lower OT doses (<21 IU) [168].

In an interesting DBPC crossover study (31 individuals with ASD, 30 control individuals) that measured the cardiac evoked and cortical evoked long-latency parietal positivity responses resulting from viewing pictures selected from the International Affective Picture System during placebo and OT treatment conditions in TD male individuals and male individuals with ASD, several factors were found to predict physiological responses. Higher baseline plasma OT levels predicted a greater treatment response in individuals with ASD [174]. Male individuals with ASD who were easily distressed when seeing others in stressful situations and male individuals with TD who were highly sensitive to anticipated punishment and criticism or had a low drive for goal achievement were found to have a higher effect [175].

\subsection{Ongoing Clinic Trials of Oxytocin There are 11} ongoing clinical trials examining of IN OT for individuals with ASD. Five studies are enrolling only children or adolescents with ASD, four studies are enrolling only adults with ASD (all but one only enrolling male individuals), and one study is enrolling both children and adults with ASD. One unique study (NCT02302209) is examining adult family members of individuals with ASD. Several studies are examining whether OT can improve standard behavior interventions or psychotherapy. For example, the quadruple-blind placebo-controlled trial (NCT01914939) is determining whether 24 IU of IN OT can enhance 20 weekly 60 -min cognitive-behavioral psychotherapy sessions concentrating on either social skills or stress management in male adults with ASD. Likewise, other studies are examining the effect of IN OT in children prior to pivotal response therapy (NCT02918864) and social cognitive skills group or facilitated play therapy (NCT03370510). One study 
(NCT0337035) is examining the addition of OT to probiotic therapy. While most studies are using a dose of 24 IU, other studies (NCT02985749, NCT01931033) are using higher doses (48 IU) while one study (NCT03466671) is directly comparing low- vs. high-dose and once- vs. twice-daily dosing. Several other studies are examining the effect of a single dose or several doses on changes in brain activity (NCT02940574, NCT03033784) or cognitive function and eye movements (NCT03183674).

Studies examining dose and frequency are particularly important as there are few data on the pharmacokinetics of IN OT as well as factors that influence the intra-subject variation in response. Indeed, nasal anatomy can influence nasal airflow dynamics, which in turn influences OT delivery and deposition on the mucosal membranes, while nasal vascularization can influence OT absorption [176]. A small study of eight healthy men suggest that 26 IU of IN OT results in a substantial rise in OT plasma levels in 30 min with levels returning to baseline $90 \mathrm{~min}$ after administration in most individuals [177]. Another study of 14 healthy ecstasy users found that 40 IU but not 20 IU of IN OT resulted in a significant increase in plasma levels within 30-60 min [178]. However, in both non-human primates [179] and rodents [180], IN OT results in a greater increase in cerebrospinal fluid OT levels as compared with plasma levels. Thus, the use of plasma OT measurements may be misleading in regard to the level of OT in the target organ.

7.1.5.2 Vasopressin Interest has developed in vasopressin, a neuropeptide that is closely associated with OT. Variants of the vasopressin receptor 1A gene (AVPR1A) in humans have also been associated with ASD [181] and IN vasopressin has been shown to modulate brain regions involved in processing emotional information, such as the medial prefrontal cortex-amygdala [182] and temporal-parietal junction [183]. In addition, knockout, rescue, and overexpression of AVPR1A in rodents modulates social function [184]. Curiously, both vasopressin agonists and antagonists are being studied in clinical trials.

In a multicenter DBPC crossover study of 19 male adults with HFASD, $20 \mathrm{mg}$ of the potent and highly selective V1a receptor antagonist, RG7713, was infused intravenously. Several exploratory measures were conducted but only one, a preference for orienting to biological motion, was statistically significant [185]. As a follow-up to this initial small pilot study, the Vasopressin Antagonist to Improve Social Communication in Autism (VANILLA) study examined another V1a receptor antagonist with good oral availability known as RG7714 (or by its trade name Balovaptan). The VANILLA study was a large $(n=223)$ multi-center DBPC dose-escalation study using three doses $(1.5 \mathrm{mg}, 4 \mathrm{mg}$, $10 \mathrm{mg}$ ), which assessed for safety and efficacy in adults with ASD. In an unpublished presentation, the drug was reported to be safe and, although the SRS did not show a significant effect, the VABS Communication and Socialization subscales, secondary outcome measures, improved for the 4- and 10-mg doses [186]. With these preliminary results, Roche was been granted FDA Breakthrough Therapy Designation for Balovaptan.

Currently, there are two clinical trials, both being conducted at Stanford University, examining the effect of IN vasopressin in ASD. One clinical trial (NCT01962870) will treat with either 12 IU or 16 IU twice a day for 4 weeks while another (NCT03204786) will examine the effect of 4 or 8 weeks of 16 IU in children. Both will provide a comprehensive assessment of social cognition as well as standard measures of change in ASD symptoms. Preliminary unpublished data suggest that the IN vasopressin improves SRS scores and that response is dependent on baseline vasopressin blood levels as well as OXTR and AVPR1A gene expression [187].

\subsection{Metabolic Agents}

\subsubsection{Folate Metabolism}

Treating central folate abnormalities in ASD has demonstrated promising results. Both small and large uncontrolled case series show that the treatment of children with ASD who are positive for $\mathrm{FR} \alpha$ autoantibodies with leucovorin calcium improves communication, social interaction, attention, and stereotypical behavior [66, 188-191] with some patients demonstrating complete recovery of core ASD symptoms [191, 192]. An open-label study of children with ASD positive for FR $\alpha$ autoantibodies $(n=44)$ and a DBPC study of a general ASD population $(n=48)$ demonstrated that leucovorin calcium primarily improves verbal communication, language, and behavior $[66,82]$. The DPBC study demonstrated a significant improvement in $\mathrm{ABC}-\mathrm{SW}$ that was greater than the minimal clinical important difference but did not show a significant effect on the SRS [82].

\subsubsection{Cobalamin Metabolism}

In a prospective open-label study $(n=37)$ of methylcobalamin $(75 \mu \mathrm{g} / \mathrm{kg})$ injected subcutaneously every 3 days combined with oral folinic acid (400 $\mu$ g twice a day) for 3 months in children with ASD who were preselected to have abnormal redox and methylation metabolism, significant improvements were found on the Social subscale of the VABS [193]. In an 8-week DBPC study of 50 children from the general ASD population, social motivation as measured by the SRS, along with the CGI-I, significantly improved with methylcobalamin subcutaneously injected $(75 \mu \mathrm{g} / \mathrm{kg}$ every 3 days) without additional oral folinic acid [194]. 


\subsubsection{N-acetyl-L-cysteine}

$\mathrm{N}$-acetyl-L-cysteine (NAC), which provides the precursor to glutathione and reduces brain glutamate, is useful for a wide range of psychiatric and neurological disorders [60] and magnetic resonance imaging studies have confirmed that it modulates brain glutamate [195]. A small $(n=33)$ 12-week study of children with ASD showed that $900 \mathrm{mg}$ of NAC three times per day improved ABC Irritability and SRS Social Motivation and CGI-I [196]. In a medium-sized $(n=40)$ DBPC add-on study to risperidone, $600 \mathrm{mg}$ of NAC twice a day significantly decreased ABC Irritability but did not change ABC-SW [197]. In a similar medium-sized $(n=40)$ risperidone add-on study, children with ASD were treated with up to $900 \mathrm{mg}$ NAC daily. $N$-acetyl-L-cysteine reduced the ABC Irritability and Hyperactivity subscales but not the ABC-SW subscale [198]. The SRS was not improved in two DBPC studies, one medium sized $(n=48)$ and one small sized $(n=16)[199,200]$. Thus, these data suggest that NAC may help with behavioral symptoms but not social symptoms in children with ASD.

\subsubsection{Tetrahydrobiopterin Metabolism}

Three controlled $(n=83,12,46)$ [201-203] and several open-label trials (total $n=280$ ) have documented improvements in communication, cognitive ability, adaptability, social abilities, and verbal expression with treatment with sapropterin, a synthetic form of $\mathrm{BH}_{4}$, in children with ASD [47]. In the two DPBC studies that measured social skills specifically, the social interaction cluster of the CARS [201] and the Social Awareness and Autism Mannerism subscales of the SRS [202] significantly improved with $\mathrm{BH}_{4}$. Interestingly, an open-label biomarker study $(n=10)$ suggested that response to sapropterin involves nitric oxide metabolism [46]. Thus, sapropterin remains an interesting potential treatment for children with ASD but given its orphan drug status for type IV hyperphenylalaninemia and no FDA-approved indication for ASD, it remains exceedingly challenging to access for routine use in the treatment of ASD.

\subsubsection{Carnitine Metabolism}

Core and associated ASD behaviors have been shown to improve with L-carnitine in two DBPC studies $(n=30$, $30)[204,205]$. Both studies used the CARS as the primary outcome measure and one study used an additional measures, the modified CGI. This is of interest because limited evidence suggests that L-carnitine is depressed in children with ASD [85] and because of a recently described genetic disorder that causes abnormal carnitine metabolism in ASD [86].

\subsubsection{Sulforaphane}

The phytochemical sulforaphane, a broccoli sprout extract, has been widely evaluated in clinical medicine, particular cancer, for its ability to upregulate intrinsic, cellular physiological protective mechanisms. In a DBPC 18-week trial of 44 young men with ASD, those receiving $50-150 \mu \mathrm{mol}$ of daily sulforaphane had a significantly greater improvement on the ABC and SRS as well as a greater number of individuals had improvement on the Ohio Autism Clinical Impression Scale Social subscale. Four weeks of discontinuation of the treatment resulted in a relapse of scores toward pretreatment levels [112]. In an open-label study of children and young adults in a school for ASD, 12 weeks of sulforaphane significantly improved the SRS [206]. Urinary metabolites associated with oxidative stress, amino acid, gut microbiome, neurotransmitters, hormones, and sphingomyelin metabolism correlated with clinical improvement.

\subsection{Microbiome Treatments}

Treatments targeting microbiome imbalances improve social behavior [207]. In a DBPC crossover study, a probiotic containing lactobacillus improved ASD behaviors, including socialization, as well as stool consistency and reduced Clostridium species [208]. However, it should be noted that this study had significant limitations including high interindividual variability and an extremely high dropout rate; of the 62 children enrolled, only 17 completed the trial. In an open-label study of children with ASD and gastrointestinal symptoms treated for 21 days with a commercial product Delpro $^{\circledR}$ that contains five probiotic strains and the immunomodulator Del-Immune $\mathrm{V}^{\circledR}, 88 \%$ of caretakers reported an improvement in ASD as measured by the Autism Treatment Evaluation Checklist [209].

A recent small $(n=18)$ open-label study replaced the gut microbiota of children, adolescents, and adults with ASD using microbiota transfer therapy. Following 2 weeks of vancomycin treatment and a bowel cleanse, gut microbiota from healthy individuals was replaced in the participants with ASD using fecal microbiota transplant for about 8 weeks. Aside from a significant reduction in gastrointestinal symptoms, improvement was also found on the CARS, ABC, and SRS scales suggesting an improvement in ASD symptoms, particularly social symptoms [210]. As an extension of this, a DBPC trial of microbiota transfer therapy in adults with ASD is ongoing (NCT03408886).

The enteric microbiome produces short-chain fatty acids known to affect metabolism and behavior. Studies from our laboratory have demonstrated that both propionic acid and butyrate, two of the most abundant short-chain fatty acids, affect mitochondrial metabolism uniquely in ASD cell lines [211, 212] and other studies demonstrate that a subset of 
children with ASD have biomarkers consistent with the propionic acid-induced ASD animal model [213]. Interestingly, butyrate may be therapeutic in normalizing social behavior in ASD as, in animal models of ASD, butyrate rescued ASD behavior in the prenatal valproic acid exposure model [214] and increased social behavior in the BTBR mouse model [215]. Despite this interesting evidence of a potential connection between the enteric microbiome and ASD symptoms, it is important to appreciate that the mechanisms by which the microbiome influences behavior are still just beginning to be understood and potentially include immune modulation, metabolic regulation, as well as altering the availability of essential nutritional substrates.

\section{Challenges in Clinical Trial Design for Studying Autism}

The heterogeneous nature of ASD presents unique challenges when conducting clinical trials [207]. Individuals with ASD have large variation in intellectual development and many have common medical co-morbidities [207]. Heterogeneity can be decreased by carefully selecting participants. Some studies target specific genetic syndromes that overlap with ASD as an extension of animal models, such as Fragile $\mathrm{X}$ $[55,216]$. Other studies select participants to match their outcome measure. Antipsychotic trials have targeted highly irritable individuals with ASD because their primary outcome measure was ABC irritability [128]. This is also an area where biomarkers can be designed to select participants predisposed to respond to targeted treatments and can help drive a precision medicine approach to drug treatment [217].

Open-label trials need to be considered cautiously especially if the trial does not have a control group. Blinded controlled trials are particularly important given the complex response to placebo. One very compelling study demonstrated that baseline factors including disruptive behavior, mood, and caregiver strain were significant negative predictors of placebo response [218]. Another factor being recognized is the nocebo response where individuals demonstrate adverse effects to placebo. Open-label trials, particularly longitudinal trials are also very vulnerable to bias depending on how drop-outs are handled, resulting in potential evaluation of a select population. Despite these limitations, open-label studies can provide useful information such as determining which outcome measure or subpopulation might be most sensitive to the effect of the treatment. Such information can be very helpful for designing better DPBC trials.

Selection of an outcome measure is important. Some studies focus on a specific outcome while other studies use a multitude of primary and/or secondary outcome measures. This is problematic and can lead to a type I error. Few studies reviewed corrected for multiple comparisons: out of the controlled studies reviewed in Table 1, only three studies corrected for multiple comparisons: one study used the Bonferroni correction [152] while two studies used the false discovery rate $[82,165]$.

Many individuals may be taking concurrent treatments and/or may be at risk for active change in their medical regime. For example, many trials exclude patients with concurring epilepsy as many antiepileptic drugs have drug-drug interactions and such individuals are at high risk for having a seizure during the trial, requiring such an event to be reported as an adverse event. Educational and behavioral therapies commonly change throughout the year and may be absent during the summer break. In addition to receiving inconsistent therapy, individuals with ASD commonly have difficulty with changes in routine.

\section{Summary}

Social deficits define ASD and result in significant disability. Overall, social function is a complex outcome to study and individuals with ASD require special considerations in clinical trials. Although there are currently no FDA-approved drugs for social deficits in individuals with ASD, several agents demonstrate promise for the treatment of this core symptom. Oxytocin and propranolol are particularly promising agents undergoing active investigation. Significant excitement has also surrounded vasopressin with both agonists and antagonists showing promise but evidence for these compounds is not peer reviewed at this time. They appear to be safe and Balobaptan, a novel compound developed by Roche, has been granted FDA Breakthrough Therapy Designation. Agents that address core ASD symptoms such as bumetanide and microbiota transfer therapy also have the potential to significantly improve social function.

\section{Compliance with Ethical Standards}

Funding No funding was received for the preparation of this article. Open access fees were paid by Dr Frye's start-up funds from Phoenix Children's Hospital.

Conflict of interest Richard E. Frye has no conflicts of interest directly relevant to the contents of this article.

Open Access This article is distributed under the terms of the Creative Commons Attribution-NonCommercial 4.0 International License (http://creativecommons.org/licenses/by-nc/4.0/), which permits any noncommercial use, distribution, and reproduction in any medium, provided you give appropriate credit to the original author(s) and the source, provide a link to the Creative Commons license, and indicate if changes were made. 


\section{References}

1. Baio J, Wiggins L, Christensen DL, Maenner MJ, Daniels J, Warren Z, Kurzius-Spencer M, Zahorodny W, Robinson Rosenberg C, White T, Durkin MS, Imm P, Nikolaou L, Yeargin-Allsopp M, Lee LC, Harrington R, Lopez M, Fitzgerald RT, Hewitt A, Pettygrove S, Constantino JN, Vehorn A, Shenouda J, Hall-Lande J, Van Naarden Braun K, Dowling NF. Prevalence of autism spectrum disorder among children aged 8 years - autism and developmental disabilities monitoring network, 11 Sites, United States, 2014. MMWR Surveill Summ. 2018;67(6):1-23. https:// doi.org/10.15585/mmwr.ss6706a1.

2. Evans B. How autism because autism: the radical transformation of a central concept of child development in Britain. Hist Human Sci. 2013;26(3):3-31.

3. Piaget J. Symbolic thought and infantile thought. Arch Psychol. 1923;18:273-304.

4. Kanner L. Autistic disturbances of affective contact. Nervous Child. 1943;2:217-50.

5. Asperger H. Die, "Autistischen Psychopathen" im Kindesalter. Archiv Psychiatrie Nervenkrankheiten. 1944;117(1):76-136.

6. Baker JP. Autism at 70: redrawing the boundaries. N Eng1 J Med. 2013;369(12):1089-91.

7. Osterling J, Dawson G. Early recognition of children with autism: a study of first birthday home videotapes. J Autism Dev Disord. 1994;24(3):247-57.

8. Osterling JA, Dawson G, Munson JA. Early recognition of 1 -year-old infants with autism spectrum disorder versus mental retardation. Dev Psychopathol. 2002;14(2):239-51.

9. Vostanis P, Smith B, Chung MC, Corbett J. Early detection of childhood autism: a review of screening instruments and rating scales. Child Care Health Dev. 1994;20(3):165-77.

10. Mitchell S, Cardy JO, Zwaigenbaum L. Differentiating autism spectrum disorder from other developmental delays in the first two years of life. Dev Disabil Res Rev. 2011;17(2):130-40. https ://doi.org/10.1002/ddrr.1107.

11. Rohlfing KJ, Grimminger A, Luke C. An interactive view on the development of deictic pointing in infancy. Front Psychol. 2017;8:1319. https://doi.org/10.3389/fpsyg.2017.01319.

12. Klin A, Jones W. Altered face scanning and impaired recognition of biological motion in a 15 -month-old infant with autism. Dev Sci. 2008;11(1):40-6. https://doi.org/10.111 1/j.1467-7687.2007.00608.x.

13. Sasson NJ, Touchstone EW. Visual attention to competing social and object images by preschool children with autism spectrum disorder. J Autism Dev Disord. 2014;44(3):584-92. https://doi. org/10.1007/s10803-013-1910-z.

14. Jones W, Klin A. Attention to eyes is present but in decline in 2-6-month-old infants later diagnosed with autism. Nature. 2013;504(7480):427-31. https://doi.org/10.1038/nature12715.

15. Berenguer C, Miranda A, Colomer C, Baixauli I, Rosello B. Contribution of theory of mind, executive functioning, and pragmatics to socialization behaviors of children with high-functioning autism. J Autism Dev Disord. 2018;48(2):430-41. https://doi. org/10.1007/s10803-017-3349-0.

16. Reinvall O, Kujala T, Voutilainen A, Moisio AL, Lahti-Nuuttila P, Laasonen M. Sluggish cognitive tempo in children and adolescents with higher functioning autism spectrum disorders: social impairments and internalizing symptoms. Scand J Psychol. 2017;58(5):389-99. https://doi.org/10.1111/sjop.12379.

17. Haigh SM, Walsh JA, Mazefsky CA, Minshew NJ, Eack SM. Processing speed is impaired in adults with autism spectrum disorder, and relates to social communication abilities. J Autism Dev Disord. 2018;48(8):2653-62. https://doi.org/10.1007/s1080 3-018-3515-z.
18. Miranda A, Berenguer C, Rosello B, Baixauli I, Colomer C. Social cognition in children with high-functioning autism spectrum disorder and attention-deficit/hyperactivity disorder: associations with executive functions. Front Psychol. 2017;8:1035. https://doi.org/10.3389/fpsyg.2017.01035.

19. Faridi F, Khosrowabadi R. Behavioral, cognitive and neural markers of Asperger syndrome. Basic Clin Neurosci. 2017;8(5):349-59. https://doi.org/10.18869/nirp.ben.8.5.349.

20. Courchesne E, Carper R, Akshoomoff N. Evidence of brain overgrowth in the first year of life in autism. JAMA. 2003;290(3):337-44.

21. Courchesne E, Karns CM, Davis HR, Ziccardi R, Carper RA, Tigue ZD, et al. Unusual brain growth patterns in early life in patients with autistic disorder: an MRI study. Neurology. 2001;57(2):245-54.

22. Bobylova MY, Petrukhin AS, Dunaevskaya GN, Piliya SV, Il'ina ES. Clinical-psychological characteristics of children with dysgenesis of the cerebellar vermis. Neurosci Behav Physiol. 2007;37(8):755-9.

23. Bauman ML, Kemper TL. Neuroanatomic observations of the brain in autism: a review and future directions. Int J Dev Neurosci. 2005;23(2-3):183-7.

24. Bauman ML, Kemper TL. Neuroanatomic observations of the brain in autism. In: Bauman ML, Kemper TL, editors. Neurobiology of autism. Baltimore: Johns Hopkins University Press; 1994. p. $119-45$.

25. Raymond GV, Bauman ML, Kemper TL. Hippocampus in autism: a Golgi analysis. Acta Neuropathol. 1996;91(1):117-9.

26. Weir RK, Bauman MD, Jacobs B, Schumann CM. Protracted dendritic growth in the typically developing human amygdala and increased spine density in young ASD brains. J Comp Neurol. 2018;526(2):262-74. https://doi.org/10.1002/cne.24332.

27. Courchesne E, Pierce K. Brain overgrowth in autism during a critical time in development: implications for frontal pyramidal neuron and interneuron development and connectivity. Int J Dev Neurosci. 2005;23(2-3):153-70.

28. Redcay E, Courchesne E. When is the brain enlarged in autism? A meta-analysis of all brain size reports. Biol Psychiatry. 2005;58(1):1-9.

29. Herbert MR. Large brains in autism: the challenge of pervasive abnormality. Neuroscientist. 2005;11(5):417-40.

30. Courchesne E, Pierce K. Why the frontal cortex in autism might be talking only to itself: local over-connectivity but long-distance disconnection. Curr Opin Neurobiol. 2005;15(2):225-30.

31. Tate DF, Bigler ED, McMahon W, Lainhart J. The relative contributions of brain, cerebrospinal fluid-filled structures and nonneural tissue volumes to occipital-frontal head circumference in subjects with autism. Neuropediatrics. 2007;38(1):18-24.

32. Shen MD, Kim SH, McKinstry RC, Gu H, Hazlett HC, Nordahl $\mathrm{CW}$, et al. Increased extra-axial cerebrospinal fluid in high-risk infants who later develop autism. Biol Psychiatry. 2017;82(3):186-93. https://doi.org/10.1016/j.biops ych.2017.02.1095.

33. Casanova MF. White matter volume increase and minicolumns in autism. Ann Neurol. 2004;56(3):453; author reply 4.

34. Li H, Xue Z, Ellmore TM, Frye RE, Wong ST. Network-based analysis reveals stronger local diffusion-based connectivity and different correlations with oral language skills in brains of children with high functioning autism spectrum disorders. Hum Brain Mapp. 2014;35(2):396-413. https://doi.org/10.1002/ hbm. 22185.

35. Casanova MF, Buxhoeveden DP, Brown C. Clinical and macroscopic correlates of minicolumnar pathology in autism. J Child Neurol. 2002;17(9):692-5.

36. Casanova M, Van Kooten I, Switala A, Van Engeland H, Heinsen $\mathrm{H}$, Steinbusch $\mathrm{H}$, et al. Abnormalities of cortical minicolumnar 
organization in the prefrontal lobes of autistic patients. Clin Neurosci Res. 2006;6:127-33.

37. Buxhoeveden DP, Casanova MF. The minicolumn hypothesis in neuroscience. Brain. 2002;125(Pt 5):935-51.

38. Mountcastle VB. The columnar organization of the neocortex. Brain. 1997;120(Pt 4):701-22.

39. DeFelipe J. Reflections on the structure of the cortical minicolumn. In: Casanova MF, editor. Neocortical modularity and the cell minicolumn. New York: Nova Biomedical; 2005. p. 57-92.

40. DeFelipe J. Chandelier cells and epilepsy. Brain. 1999;122(Pt 10):1807-22.

41. DeFelipe J, Hendry SH, Hashikawa T, Molinari M, Jones EG. A microcolumnar structure of monkey cerebral cortex revealed by immunocytochemical studies of double bouquet cell axons. Neuroscience. 1990;37(3):655-73.

42. Favorov OV, Kelly DG. Minicolumnar organization within somatosensory cortical segregates: II. Emergent functional properties. Cereb Cortex. 1994;4(4):428-42.

43. Subramanian K, Brandenburg C, Orsati F, Soghomonian JJ, Hussman JP, Blatt GJ. Basal ganglia and autism: a translational perspective. Autism Res. 2017;10(11):1751-75. https://doi. org/10.1002/aur.1837.

44. Stoodley CJ, Schmahmann JD. Evidence for topographic organization in the cerebellum of motor control versus cognitive and affective processing. Cortex. 2010;46(7):831-44. https://doi. org/10.1016/j.cortex.2009.11.008.

45. Frye RE. Central tetrahydrobiopterin concentration in neurodevelopmental disorders. Front Neurosci. 2010;4:52. https://doi. org/10.3389/fnins.2010.00052.

46. Frye RE, DeLatorre R, Taylor HB, Slattery J, Melnyk S, Chowdhury N, et al. Metabolic effects of sapropterin treatment in autism spectrum disorder: a preliminary study. Transl Psychiatry. 2013;3:e237. https://doi.org/10.1038/tp.2013.14.

47. Frye RE, Huffman LC, Elliott GR. Tetrahydrobiopterin as a novel therapeutic intervention for autism. Neurotherapeutics. 2010;7(3):241-9. https://doi.org/10.1016/j.nurt.2010.05.004.

48. Rossignol DA, Frye RE. The use of medications approved for Alzheimer's disease in autism spectrum disorder: a systematic review. Front Pediatr. 2014;2:87. https://doi.org/10.3389/ fped.2014.00087.

49. Oberman LM. mGluR antagonists and GABA agonists as novel pharmacological agents for the treatment of autism spectrum disorders. Expert Opin Investig Drugs. 2012;21(12):1819-25. https ://doi.org/10.1517/13543784.2012.729819.

50. Cellot G, Cherubini E. GABAergic signaling as therapeutic target for autism spectrum disorders. Front Pediatr. 2014;2:70. https:// doi.org/10.3389/fped.2014.00070.

51. Casanova MF, Buxhoeveden D, Gomez J. Disruption in the inhibitory architecture of the cell minicolumn: implications for autism. Neuroscientist. 2003;9(6):496-507. https://doi. org/10.1177/1073858403253552.

52. Rubenstein JL, Merzenich MM. Model of autism: increased ratio of excitation/inhibition in key neural systems. Genes Brain Behav. 2003;2(5):255-67.

53. Grothe B, Klump GM. Temporal processing in sensory systems. Curr Opin Neurobiol. 2000;10(4):467-73.

54. Webb S. Drugmakers dance with autism. Nat Biotechnol. 2010;28(8):772-4. https://doi.org/10.1038/nbt0810-772.

55. Frye RE. Clinical potential, safety, and tolerability of arbaclofen in the treatment of autism spectrum disorder. Drug Healthc Patient Saf. 2014;6:69-76. https://doi.org/10.2147/DHPS.S3959 5.

56. Ben-Ari Y. NKCC1 chloride importer antagonists attenuate many neurological and psychiatric dsorders. Trends Neurosci. 2017;40(9):536-54. https://doi.org/10.1016/j.tins.2017.07.001.
57. Maloney SE, Rieger MA, Dougherty JD. Identifying essential cell types and circuits in autism spectrum disorders. Int Rev Neurobiol. 2013;113:61-96. https://doi.org/10.1016/B978-012-418700-9.00003-4.

58. Rose S, Melnyk S, Pavliv O, Bai S, Nick TG, Frye RE, et al. Evidence of oxidative damage and inflammation associated with low glutathione redox status in the autism brain. Transl Psychiatry. 2012;2:e134. https://doi.org/10.1038/tp.2012.61.

59. Rossignol DA, Frye RE. Evidence linking oxidative stress, mitochondrial dysfunction, and inflammation in the brain of individuals with autism. Front Physiol. 2014;5:150. https://doi. org/10.3389/fphys.2014.00150.

60. Deepmala D, Slattery J, Kumar N, Delhey L, Berk M, Dean O, et al. Clinical trials of $N$-acetylcysteine in psychiatry and neurology: a systematic review. Neurosci Biobehav Rev. 2015;55:294321. https://doi.org/10.1016/j.neubiorev.2015.04.015.

61. Frye RE, James SJ. Metabolic pathology of autism in relation to redox metabolism. Biomark Med. 2014;8(3):321-30. https://doi. org/10.2217/bmm.13.158.

62. Frye RE. Metabolic and mitochondrial disorders associated with epilepsy in children with autism spectrum disorder. Epilepsy Behav. 2015;47:147-57. https://doi.org/10.1016/j.yebeh .2014.08.134.

63. Rossignol DA, Frye RE. Mitochondrial dysfunction in autism spectrum disorders: a systematic review and meta-analysis. Mol Psychiatry. 2012;17(3):290-314. https://doi.org/10.1038/ mp.2010.136.

64. Frye RE, Casanova MF, Fatemi SH, Folsom TD, Reutiman TJ, Brown GL, et al. Neuropathological mechanisms of seizures in autism spectrum disorder. Front Neurosci. 2016;10:192. https:// doi.org/10.3389/fnins.2016.00192.

65. Frye RE, Rossignol DA. Treatments for biomedical abnormalities associated with autism spectrum disorder. Front Pediatr. 2014;2:66. https://doi.org/10.3389/fped.2014.00066.

66. Frye RE, Sequeira JM, Quadros EV, James SJ, Rossignol DA. Cerebral folate receptor autoantibodies in autism spectrum disorder. Mol Psychiatry. 2013;18(3):369-81. https://doi.org/10.1038/ mp.2011.175.

67. Lefevre A, Sirigu A. The two fold role of oxytocin in social developmental disorders: a cause and a remedy? Neurosci Biobehav Rev. 2016;63:168-76. https://doi.org/10.1016/j.neubi orev.2016.01.011.

68. Wigton R, Radua J, Allen P, Averbeck B, Meyer-Lindenberg A, McGuire P, et al. Neurophysiological effects of acute oxytocin administration: systematic review and meta-analysis of placebo-controlled imaging studies. J Psychiatry Neurosci. 2015;40(1):E1-22.

69. Obeid R, McCaddon A, Herrmann W. The role of hyperhomocysteinemia and B-vitamin deficiency in neurological and psychiatric diseases. Clin Chem Lab Med. 2007;45(12):1590-606. https://doi.org/10.1515/CCLM.2007.356.

70. Frye RE, Slattery JC, Quadros EV. Folate metabolism abnormalities in autism: potential biomarkers. Biomark Med. 2017. https ://doi.org/10.2217/bmm-2017-0109.

71. Frustaci A, Neri M, Cesario A, Adams JB, Domenici E, Dalla Bernardina B, et al. Oxidative stress-related biomarkers in autism: systematic review and meta-analyses. Free Radic Biol Med. 2012;52(10):2128-41. https://doi.org/10.1016/j.freeradbio med.2012.03.011.

72. Boris M, Goldblatt A, Galanko J, James SJ. Association of MTHFR gene variants with autism. J Am Physicians Surg. 2004;9(4):106-8.

73. Mohammad NS, Jain JM, Chintakindi KP, Singh RP, Naik U, Akella RR. Aberrations in folate metabolic pathway and altered susceptibility to autism. Psychiatr Genet. 2009;19(4):171-6. https://doi.org/10.1097/YPG.0b013e32832cebd2. 
74. Guo T, Chen H, Liu B, Ji W, Yang C. Methylenetetrahydrofolate reductase polymorphisms C677T and risk of autism in the Chinese Han population. Genet Test Mol Biomarkers. 2012;16(8):968-73. https://doi.org/10.1089/gtmb.2012.0091.

75. Schmidt RJ, Tancredi DJ, Ozonoff S, Hansen RL, Hartiala J, Allayee $\mathrm{H}$, et al. Maternal periconceptional folic acid intake and risk of autism spectrum disorders and developmental delay in the CHARGE (CHildhood Autism Risks from Genetics and Environment) case-control study. Am J Clin Nutr. 2012;96(1):80-9. https ://doi.org/10.3945/ajcn.110.004416.

76. Liu X, Solehdin F, Cohen IL, Gonzalez MG, Jenkins EC, Lewis ME, et al. Population- and family-based studies associate the MTHFR gene with idiopathic autism in simplex families. J Autism Dev Disord. 2011;41(7):938-44. https://doi.org/10.1007/ s10803-010-1120-x.

77. Goin-Kochel RP, Porter AE, Peters SU, Shinawi M, Sahoo $\mathrm{T}$, Beaudet AL. The MTHFR $677 \mathrm{C} \rightarrow \mathrm{T}$ polymorphism and behaviors in children with autism: exploratory genotype-phenotype correlations. Autism Res. 2009;2(2):98-108. https://doi. org/10.1002/aur.70.

78. Pasca SP, Dronca E, Kaucsar T, Craciun EC, Endreffy E, Ferencz $\mathrm{BK}$, et al. One carbon metabolism disturbances and the C677T MTHFR gene polymorphism in children with autism spectrum disorders. J Cell Mol Med. 2009;13(10):4229-38. https://doi.org /10.1111/j.1582-4934.2008.00463.x.

79. James SJ, Melnyk S, Jernigan S, Cleves MA, Halsted CH, Wong $\mathrm{DH}$, et al. Metabolic endophenotype and related genotypes are associated with oxidative stress in children with autism. Am J Med Genet B Neuropsychiatr Genet. 2006;141B(8):947-56. https ://doi.org/10.1002/ajmg.b.30366.

80. Pu D, Shen Y, Wu J. Association between MTHFR gene polymorphisms and the risk of autism spectrum disorders: a metaanalysis. Autism Res. 2013;6(5):384-92. https://doi.org/10.1002/ aur. 1300 .

81. Adams M, Lucock M, Stuart J, Fardell S, Baker K, Ng X. Preliminary evidence for involvement of the folate gene polymorphism $19 \mathrm{bp}$ deletion-DHFR in occurrence of autism. Neurosci Lett. 2007;422(1):24-9. https://doi.org/10.1016/j.neulet.2007.05.025.

82. Frye RE, Slattery J, Delhey L, Furgerson B, Strickland T, Tippett $\mathrm{M}$, et al. Folinic acid improves verbal communication in children with autism and language impairment: a randomized doubleblind placebo-controlled trial. Mol Psychiatry. 2018;23(2):24756. https://doi.org/10.1038/mp.2016.168.

83. Frye RE, Delhey L, Slattery J, Tippett M, Wynne R, Rose S, et al. Blocking and binding folate receptor alpha autoantibodies identify novel autism spectrum disorder subgroups. Front Neurosci. 2016;10:80. https://doi.org/10.3389/fnins.2016.00080.

84. Zhang Y, Hodgson NW, Trivedi MS, Abdolmaleky HM, Fournier M, Cuenod M, et al. Decreased brain levels of vitamin $\mathrm{B}_{12}$ in aging, autism and schizophrenia. PLoS One. 2016;11(1):e0146797. https://doi.org/10.1371/journ al.pone. 0146797 .

85. Filipek PA, Juranek J, Nguyen MT, Cummings C, Gargus JJ. Relative carnitine deficiency in autism. J Autism Dev Disord. 2004;34(6):615-23.

86. Celestino-Soper PB, Violante S, Crawford EL, Luo R, Lionel AC, Delaby E, et al. A common X-linked inborn error of carnitine biosynthesis may be a risk factor for nondysmorphic autism. Proc Natl Acad Sci USA. 2012;109(21):7974-81. https://doi. org/10.1073/pnas.1120210109.

87. Frye RE, Rossignol D. Metabolic disorders and abnormalities associated with autism spectrum disorder. J Pediatr Biochem. 2012;2:181-91.

88. Ashwood P, Wills S, Van de Water J. The immune response in autism: a new frontier for autism research. J Leukoc Biol. 2006;80(1):1-15.
89. Braunschweig D, Krakowiak P, Duncanson P, Boyce R, Hansen RL, Ashwood P, et al. Autism-specific maternal autoantibodies recognize critical proteins in developing brain. Transl Psychiatry. 2013;3:e277. https://doi.org/10.1038/tp.2013.50.

90. Vargas DL, Nascimbene C, Krishnan C, Zimmerman AW, Pardo CA. Neuroglial activation and neuroinflammation in the brain of patients with autism. Ann Neurol. 2005;57(1):67-81. https://doi. org/10.1002/ana.20315.

91. Diaz Heijtz R, Wang S, Anuar F, Qian Y, Bjorkholm B, Samuelsson A, et al. Normal gut microbiota modulates brain development and behavior. Proc Natl Acad Sci USA. 2011;108(7):3047-52. https://doi.org/10.1073/pnas.1010529108.

92. Wang L, Christophersen CT, Sorich MJ, Gerber JP, Angley MT, Conlon MA. Increased abundance of Sutterella spp. and Ruminococcus torques in feces of children with autism spectrum disorder. Mol. Autism. 2013;4(1):42. https://doi. org/10.1186/2040-2392-4-42.

93. Wang L, Conlon MA, Christophersen CT, Sorich MJ, Angley MT. Gastrointestinal microbiota and metabolite biomarkers in children with autism spectrum disorders. Biomark Med. 2014;8(3):331-44. https://doi.org/10.2217/bmm.14.12.

94. Williams BL, Hornig M, Buie T, Bauman ML, Cho Paik M, Wick I, et al. Impaired carbohydrate digestion and transport and mucosal dysbiosis in the intestines of children with autism and gastrointestinal disturbances. PLoS One. 2011;6(9):e24585. https ://doi.org/10.1371/journal.pone.0024585.

95. Kang DW, Park JG, Ilhan ZE, Wallstrom G, Labaer J, Adams JB, et al. Reduced incidence of Prevotella and other fermenters in intestinal microflora of autistic children. PLoS One. 2013;8(7):e68322. https://doi.org/10.1371/journal.pone.00683 22.

96. Krajmalnik-Brown R, Lozupone C, Kang DW, Adams JB. Gut bacteria in children with autism spectrum disorders: challenges and promise of studying how a complex community influences a complex disease. Microb Ecol Health Dis. 2015;26:26914. https ://doi.org/10.3402/mehd.v26.26914.

97. Bilbo SD, Nevison CD, Parker W. A model for the induction of autism in the ecosystem of the human body: the anatomy of a modern pandemic? Microb Ecol Health Dis. 2015;26:26253. https://doi.org/10.3402/mehd.v26.26253.

98. De Angelis M, Piccolo M, Vannini L, Siragusa S, De Giacomo A, Serrazzanetti DI, et al. Fecal microbiota and metabolome of children with autism and pervasive developmental disorder not otherwise specified. PLoS One. 2013;8(10):e76993. https://doi. org/10.1371/journal.pone.0076993.

99. Buie T. Potential etiologic factors of microbiome disruption in autism. Clin Ther. 2015;37(5):976-83. https://doi.org/10.1016/j. clinthera.2015.04.001.

100. Finegold SM. Desulfovibrio species are potentially important in regressive autism. Med Hypotheses. 2011;77(2):270-4. https:// doi.org/10.1016/j.mehy.2011.04.032.

101. Sandler RH, Finegold SM, Bolte ER, Buchanan CP, Maxwell AP, Vaisanen ML, et al. Short-term benefit from oral vancomycin treatment of regressive-onset autism. J Child Neurol. 2000;15(7):429-35.

102. Hsiao EY, McBride SW, Hsien S, Sharon G, Hyde ER, McCue $\mathrm{T}$, et al. Microbiota modulate behavioral and physiological abnormalities associated with neurodevelopmental disorders. Cell. 2013;155(7):1451-63. https://doi.org/10.1016/j. cell.2013.11.024.

103. Fernandez M, Mollinedo-Gajate I, Penagarikano O. Neural circuits for social cognition: implications for autism. Neuroscience. 2018;370:148-62. https://doi.org/10.1016/j.neuroscien ce.2017.07.013.

104. Soto-Icaza P, Aboitiz F, Billeke P. Development of social skills in children: neural and behavioral evidence for the elaboration 
of cognitive models. Front Neurosci. 2015;9:333. https://doi. org/10.3389/fnins.2015.00333.

105. Ha S, Sohn IJ, Kim N, Sim HJ, Cheon KA. Characteristics of brains in autism spectrum disorder: structure, function and connectivity across the lifespan. Exp Neurobiol. 2015;24(4):273-84. https://doi.org/10.5607/en.2015.24.4.273.

106. Hull JV, Jacokes ZJ, Torgerson CM, Irimia A, Van Horn JD. Resting-state functional connectivity in autism spectrum disorders: a review. Front Psychiatry. 2016;7:205. https://doi. org/10.3389/fpsyt.2016.00205.

107. Aman MG, Findling RL, Hardan AY, Hendren RL, Melmed RD, Kehinde-Nelson O, et al. Safety and efficacy of memantine in children with autism: randomized, placebo-controlled study and open-label extension. J Child Adolesc Psychopharmacol. 2017;27(5):403-12. https://doi.org/10.1089/cap.2015.0146.

108. Wolstencroft J, Robinson L, Srinivasan R, Kerry E, Mandy W, Skuse D. A systematic review of group social skills interventions, and meta-analysis of outcomes, for children with high functioning ASD. J Autism Dev Disord. 2018;48(7):2293-307. https://doi.org/10.1007/s10803-018-3485-1.

109. Scahill L, Bearss K, Sarhangian R, McDougle CJ, Arnold LE, Aman MG, et al. Using a patient-centered outcome measure to test methylphenidate versus placebo in children with autism spectrum disorder. J Child Adolesc Psychopharmacol. 2017;27(2):125-31. https://doi.org/10.1089/cap.2016.0107.

110. TORUoP P. OSU Autism Rating Scale: DSM-IV (OARS-4). Columbus: Children's Research Institute; 2005.

111. Choque Olsson N, Bolte S. Brief report: "Quick and (not so) dirty" assessment of change in autism: cross-cultural reliability of the Developmental Disabilities CGAS and the OSU autism CGI. J Autism Dev Disord. 2014;44(7):1773-8. https://doi. org/10.1007/s10803-013-2029-y.

112. Singh K, Connors SL, Macklin EA, Smith KD, Fahey JW, Talalay P, et al. Sulforaphane treatment of autism spectrum disorder (ASD). Proc Natl Acad Sci USA. 2014;111(43):15550-5. https ://doi.org/10.1073/pnas.1416940111.

113. Dadds MR, MacDonald E, Cauchi A, Williams K, Levy F, Brennan J. Nasal oxytocin for social deficits in childhood autism: a randomized controlled trial. J Autism Dev Disord. 2014;44(3):521-31. https://doi.org/10.1007/s10803-013-1899-3.

114. Morrier MJ, Ousley OY, Caceres-Gamundi GA, Segall MJ, Cubells JF, Young LJ, et al. Brief report: relationship between ADOS-2, Module 4 Calibrated Severity Scores (CSS) and social and non-social standardized assessment measures in adult males with autism spectrum disorder (ASD). J Autism Dev Disord. 2017;47(12):4018-24. https://doi.org/10.1007/s 1080 3-017-3293-z

115. Shumway S, Farmer C, Thurm A, Joseph L, Black D, Golden C. The ADOS calibrated severity score: relationship to phenotypic variables and stability over time. Autism Res. 2012;5(4):267-76. https://doi.org/10.1002/aur.1238.

116. Wiggins LD, Barger B, Moody E, Soke G, Pandey J, Levy S. Brief report: the ADOS calibrated severity score best measures autism diagnostic symptom severity in pre-school children. J Autism Dev Disord. 2017. https://doi.org/10.1007/s1080 3-017-3072-x.

117. Grzadzinski R, Carr T, Colombi C, McGuire K, Dufek S, Pickles A, et al. Measuring changes in social communication behaviors: preliminary development of the Brief Observation of Social Communication Change (BOSCC). J Autism Dev Disord. 2016;46(7):2464-79. https://doi.org/10.1007/s1080 3-016-2782-9.

118. Stichter JP, Herzog MJ, O'Connor KV, Schmidt C. A preliminary examination of a general social outcome measure. Assess Eff Interv. 2012;38(1):40-52. https://doi.org/10.1177/1534508412 455213.
119. Tatsumi Y, Mohri I, Shimizu S, Tachibana M, Ohno Y, Taniike M. Daytime physical activity and sleep in pre-schoolers with developmental disorders. J Paediatr Child Health. 2015;51(4):396-402. https://doi.org/10.1111/jpc.12725.

120. Kang JY, Kim R, Kim H, Kang Y, Hahn S, Fu Z, et al. Automated tracking and quantification of autistic behavioral symptoms using Microsoft Kinect. Stud Health Technol Inform. 2016;220:167-70.

121. Papagiannopoulou EA, Chitty KM, Hermens DF, Hickie IB, Lagopoulos J. A systematic review and meta-analysis of eyetracking studies in children with autism spectrum disorders. Soc Neurosci. 2014;9(6):610-32. https://doi.org/10.1080/17470 919.2014.934966.

122. Tonge BJ, Bull K, Brereton A, Wilson R. A review of evidencebased early intervention for behavioural problems in children with autism spectrum disorder: the core components of effective programs, child-focused interventions and comprehensive treatment models. Curr Opin Psychiatry. 2014;27(2):158-65. https:// doi.org/10.1097/YCO.0000000000000043.

123. Reichow B, Barton EE, Boyd BA, Hume K. Early intensive behavioral intervention (EIBI) for young children with autism spectrum disorders (ASD). Cochrane Database Syst Rev. 2012;10:009260. https://doi.org/10.1002/14651858.cd009260. pub2.

124. Karst JS, Van Hecke AV. Parent and family impact of autism spectrum disorders: a review and proposed model for intervention evaluation. Clin Child Fam Psychol Rev. 2012;15(3):24777. https://doi.org/10.1007/s10567-012-0119-6.

125. Broder-Fingert S, Shui A, Pulcini CD, Kurowski D, Perrin JM. Racial and ethnic differences in subspecialty service use by children with autism. Pediatrics. 2013;132(1):94-100. https://doi. org/10.1542/peds.2012-3886.

126. Magiati I, Tay XW, Howlin P. Cognitive, language, social and behavioural outcomes in adults with autism spectrum disorders: a systematic review of longitudinal follow-up studies in adulthood. Clin Psychol Rev. 2014;34(1):73-86. https://doi.org/10.1016/j. cpr.2013.11.002.

127. Scahill L, Hallett V, Aman MG, McDougle CJ, Eugene Arnold L, McCracken JT, et al. Brief report: social disability in autism spectrum disorder: results from Research Units on Pediatric Psychopharmacology (RUPP) Autism Network trials. J Autism Dev Disord. 2013;43(3):739-46. https://doi.org/10.1007/s1080 3-012-1689-3.

128. McCracken JT, McGough J, Shah B, Cronin P, Hong D, Aman $\mathrm{MG}$, et al. Risperidone in children with autism and serious behavioral problems. N Engl J Med. 2002;347(5):314-21. https ://doi.org/10.1056/NEJMoa013171.

129. Aman MG, McDougle CJ, Scahill L, Handen B, Arnold LE, Johnson C, et al. Medication and parent training in children with pervasive developmental disorders and serious behavior problems: results from a randomized clinical trial. J Am Acad Child Adolesc Psychiatry. 2009;48(12):1143-54. https://doi. org/10.1097/CHI.0b013e3181bfd669.

130. Nagaraj R, Singhi P, Malhi P. Risperidone in children with autism: randomized, placebo-controlled, double-blind study. J Child Neurol. 2006;21(6):450-5. https://doi.org/10.1177/08830 738060210060801.

131. Aman M, Rettiganti M, Nagaraja HN, Hollway JA, McCracken $\mathrm{J}, \mathrm{McDougle} \mathrm{CJ}$, et al. Tolerability, safety, and benefits of risperidone in children and adolescents with autism: 21-month follow-up after 8-week placebo-controlled trial. J Child Adolesc Psychopharmacol. 2015;25(6):482-93. https://doi.org/10.1089/ cap.2015.0005.

132. Marrus N, Underwood-Riordan H, Randall F, Zhang Y, Constantino JN. Lack of effect of risperidone on core autistic symptoms: data from a longitudinal study. J Child Adolesc 
Psychopharmacol. 2014;24(9):513-8. https://doi.org/10.1089/ cap.2014.0055.

133. Correll CU, Manu P, Olshanskiy V, Napolitano B, Kane JM, Malhotra AK. Cardiometabolic risk of second-generation antipsychotic medications during first-time use in children and adolescents. JAMA. 2009;302(16):1765-73. https://doi.org/10.1001/ jama.2009.1549.

134. Wink LK, Early M, Schaefer T, Pottenger A, Horn P, McDougle $\mathrm{CJ}$, et al. Body mass index change in autism spectrum disorders: comparison of treatment with risperidone and aripiprazole. J Child Adolesc Psychopharmacol. 2014;24(2):78-82. https:// doi.org/10.1089/cap.2013.0099.

135. Scahill L, Hallett V, Aman MG, McDougle CJ, Eugene Arnold L, McCracken JT, et al. Brief report: social disability in autism spectrum disorder: results from Research Units on Pediatric Psychopharmacology (RUPP) Autism Network trials. J Autism Develop Disord. 2013;43(3):739-46. https://doi.org/10.1007/ s10803-012-1689-3.

136. Bobo WV, Cooper WO, Stein CM, Olfson M, Graham D, Daugherty J, et al. Antipsychotics and the risk of type 2 diabetes mellitus in children and youth. JAMA Psychiatry. 2013;70(10):106775. https://doi.org/10.1001/jamapsychiatry.2013.2053.

137. Correll CU, Kane JM. One-year incidence rates of tardive dyskinesia in children and adolescents treated with secondgeneration antipsychotics: a systematic review. J Child Adolesc Psychopharmacol. 2007;17(5):647-56. https://doi.org/10.1089/ cap.2006.0117.

138. Erickson CA, Veenstra-Vanderweele JM, Melmed RD, McCracken JT, Ginsberg LD, Sikich L, et al. STX209 (arbaclofen) for autism spectrum disorders: an 8-week open-label study. J Autism Dev Disord. 2014;44(4):958-64. https://doi. org/10.1007/s10803-013-1963-z.

139. Delahunty C, Walton-Bowen K, Kuriyama N, Cherubini M, Carpenter R, Bear M, et al. Randomized, controlled, phase 2 trial of STX209 (arbaclofen) for social function in ASD. Paper Presented at the American Academy of Pediatrics (AAP) 2013 National Conference and Exhibition, Orlando, FL, October 26-29, 2013.

140. Lemonnier E, Degrez C, Phelep M, Tyzio R, Josse F, Grandgeorge $\mathrm{M}$, et al. A randomised controlled trial of bumetanide in the treatment of autism in children. Transl Psychiatry. 2012;2:e202. https://doi.org/10.1038/tp.2012.124.

141. Lemonnier E, Villeneuve N, Sonie S, Serret S, Rosier A, Roue $\mathrm{M}$, et al. Effects of bumetanide on neurobehavioral function in children and adolescents with autism spectrum disorders. Transl Psychiatry. 2017;7(3):e1056. https://doi.org/10.1038/tp.2017.10.

142. Hadjikhani N, Zurcher NR, Rogier O, Ruest T, Hippolyte L, BenAri Y, et al. Improving emotional face perception in autism with diuretic bumetanide: a proof-of-concept behavioral and functional brain imaging pilot study. Autism. 2015;19(2):149-57. https://doi.org/10.1177/1362361313514141.

143. Hadjikhani N, Asberg Johnels J, Lassalle A, Zurcher NR, Hippolyte L, Gillberg C, et al. Bumetanide for autism: more eye contact, less amygdala activation. Sci Rep. 2018;8(1):3602. https://doi. org/10.1038/s41598-018-21958-x.

144. Chez M, Hung PC, Chin K, Memon S, Kirschner S. Memantine experience in children and adolescents with autistic spectrum disorders. Ann Neurol. 2004;56(Suppl. 8):109.

145. Erickson CA, Posey DJ, Stigler KA, Mullett J, Katschke AR, McDougle CJ. A retrospective study of memantine in children and adolescents with pervasive developmental disorders. Psychopharmacology (Berl). 2007;191(1):141-7. https://doi. org/10.1007/s00213-006-0518-9.

146. Chez MG, Burton Q, Dowling T, Chang M, Khanna P, Kramer C. Memantine as adjunctive therapy in children diagnosed with autistic spectrum disorders: an observation of initial clinical response and maintenance tolerability. J Child Neurol. 2007;22(5):574-9. https://doi.org/10.1177/0883073807302611.

147. Joshi G, Wozniak J, Faraone SV, Fried R, Chan J, Furtak S, et al. A prospective open-label trial of memantine hydrochloride for the treatment of social deficits in intellectually capable adults with autism spectrum disorder. J Clin Psychopharmacol. 2016;36(3):262-71. https://doi.org/10.1097/jcp.0000000000 000499.

148. Ghaleiha A, Asadabadi M, Mohammadi MR, Shahei M, Tabrizi M, Hajiaghaee R, et al. Memantine as adjunctive treatment to risperidone in children with autistic disorder: a randomized, double-blind, placebo-controlled trial. Int J Neuropsychopharmacol. 2013;16(4):783-9. https://doi.org/10.1017/S146114571 2000880.

149. Ratey JJ, Bemporad J, Sorgi P, Bick P, Polakoff S, O’Driscoll $\mathrm{G}$, et al. Open trial effects of beta-blockers on speech and social behaviors in 8 autistic adults. J Autism Dev Disord. 1987;17(3):439-46.

150. Deepmala D, Agrawal M. Use of propranolol for hypersexual behavior in an adolescent with autism. Ann Pharmacother. 2014;48(10):1385-8. https://doi.org/10.1177/106002801454163 0 .

151. Zamzow RM, Ferguson BJ, Stichter JP, Porges EC, Ragsdale AS, Lewis ML, et al. Effects of propranolol on conversational reciprocity in autism spectrum disorder: a pilot, double-blind, single-dose psychopharmacological challenge study. Psychopharmacology (Berl). 2016;233(7):1171-8. https://doi.org/10.1007/ s00213-015-4199-0.

152. Zamzow RM, Christ SE, Saklayen SS, Moffitt AJ, Bodner $\mathrm{KE}$, Higgins KF, et al. Effect of propranolol on facial scanning in autism spectrum disorder: a preliminary investigation. J Clin Exp Neuropsychol. 2014;36(4):431-45. https://doi. org/10.1080/13803395.2014.904844.

153. Zamzow RM, Ferguson BJ, Ragsdale AS, Lewis ML, Beversdorf DQ. Effects of acute beta-adrenergic antagonism on verbal problem solving in autism spectrum disorder and exploration of treatment response markers. J Clin Exp Neuropsychol. 2017;39(6):596-606. https://doi.org/10.1080/13803 395.2016.1252724.

154. Beversdorf DQ, Saklayen S, Higgins KF, Bodner KE, Kanne SM, Christ SE. Effect of propranolol on word fluency in autism. Cogn Behav Neurol. 2011;24(1):11-7. https://doi.org/10.1097/ WNN.0b013e318204d20e.

155. Bodner KE, Beversdorf DQ, Saklayen SS, Christ SE. Noradrenergic moderation of working memory impairments in adults with autism spectrum disorder. J Int Neuropsychol Soc. 2012;18(3):556-64. https://doi.org/10.1017/s13556177120000 70.

156. Narayanan A, White CA, Saklayen S, Scaduto MJ, Carpenter AL, Abduljalil A, et al. Effect of propranolol on functional connectivity in autism spectrum disorder: a pilot study. Brain Imaging Behav. 2010;4(2):189-97. https://doi.org/10.1007/s1168 2-010-9098-8.

157. Hegarty JP 2nd, Ferguson BJ, Zamzow RM, Rohowetz LJ, Johnson JD, Christ SE, et al. Beta-adrenergic antagonism modulates functional connectivity in the default mode network of individuals with and without autism spectrum disorder. Brain Imaging Behav. 2017;11(5):1278-89. https://doi.org/10.1007/s1168 2-016-9604-8.

158. Hollander E, Novotny S, Hanratty M, Yaffe R, DeCaria CM, Aronowitz BR, et al. Oxytocin infusion reduces repetitive behaviors in adults with autistic and Asperger's disorders. Neuropsychopharmacology. 2003;28(1):193-8. https://doi.org/10.1038/ sj.npp.1300021. 
159. Hollander E, Bartz J, Chaplin W, Phillips A, Sumner J, Soorya $\mathrm{L}$, et al. Oxytocin increases retention of social cognition in autism. Biol Psychiatry. 2007;61(4):498-503. https://doi. org/10.1016/j.biopsych.2006.05.030.

160. Guastella AJ, Einfeld SL, Gray KM, Rinehart NJ, Tonge BJ, Lambert TJ, et al. Intranasal oxytocin improves emotion recognition for youth with autism spectrum disorders. Biol Psychiatry. 2010;67(7):692-4. https://doi.org/10.1016/j.biops ych.2009.09.020.

161. Auyeung B, Lombardo MV, Heinrichs M, Chakrabarti B, Sule A, Deakin JB, et al. Oxytocin increases eye contact during a real-time, naturalistic social interaction in males with and without autism. Transl Psychiatry. 2015;5:e507. https://doi. org/10.1038/tp.2014.146.

162. Kanat M, Spenthof I, Riedel A, van Elst LT, Heinrichs M, Domes G. Restoring effects of oxytocin on the attentional preference for faces in autism. Transl Psychiatry. 2017;7(4):e1097. https://doi.org/10.1038/tp.2017.67.

163. Anagnostou E, Soorya L, Chaplin W, Bartz J, Halpern D, Wasserman S, et al. Intranasal oxytocin versus placebo in the treatment of adults with autism spectrum disorders: a randomized controlled trial. Mol Autism. 2012;3(1):16. https://doi. org/10.1186/2040-2392-3-16.

164. Tachibana M, Kagitani-Shimono K, Mohri I, Yamamoto T, Sanefuji W, Nakamura A, et al. Long-term administration of intranasal oxytocin is a safe and promising therapy for early adolescent boys with autism spectrum disorders. J Child Adolesc Psychopharmacol. 2013;23(2):123-7. https://doi. org/10.1089/cap.2012.0048.

165. Watanabe T, Kuroda M, Kuwabara H, Aoki Y, Iwashiro N, Tatsunobu N, et al. Clinical and neural effects of six-week administration of oxytocin on core symptoms of autism. Brain. 2015;138(Pt 11):3400-12. https://doi.org/10.1093/brain/awv249.

166. Yatawara CJ, Einfeld SL, Hickie IB, Davenport TA, Guastella AJ. The effect of oxytocin nasal spray on social interaction deficits observed in young children with autism: a randomized clinical crossover trial. Mol Psychiatry. 2016;21(9):1225-31. https://doi. org/10.1038/mp.2015.162.

167. Guastella AJ, Gray KM, Rinehart NJ, Alvares GA, Tonge BJ, Hickie IB, et al. The effects of a course of intranasal oxytocin on social behaviors in youth diagnosed with autism spectrum disorders: a randomized controlled trial. J Child Psychol Psychiatry. 2015;56(4):444-52. https://doi.org/10.1111/jcpp.12305.

168. Kosaka H, Okamoto Y, Munesue T, Yamasue H, Inohara K, Fujioka T, et al. Oxytocin efficacy is modulated by dosage and oxytocin receptor genotype in young adults with high-functioning autism: a 24-week randomized clinical trial. Transl Psychiatry. 2016;6(8):e872. https://doi.org/10.1038/tp.2016.152.

169. Domes G, Heinrichs M, Kumbier E, Grossmann A, Hauenstein $\mathrm{K}$, Herpertz SC. Effects of intranasal oxytocin on the neural basis of face processing in autism spectrum disorder. Biol Psychiatry. 2013;74(3):164-71. https://doi.org/10.1016/j.biops ych.2013.02.007.

170. Watanabe T, Abe O, Kuwabara H, Yahata N, Takano Y, Iwashiro $\mathrm{N}$, et al. Mitigation of sociocommunicational deficits of autism through oxytocin-induced recovery of medial prefrontal activity: a randomized trial. JAMA Psychiatry. 2014;71(2):166-75. https ://doi.org/10.1001/jamapsychiatry.2013.3181.

171. Aoki Y, Watanabe T, Abe O, Kuwabara H, Yahata N, Takano Y, et al. Oxytocin's neurochemical effects in the medial prefrontal cortex underlie recovery of task-specific brain activity in autism: a randomized controlled trial. Mol Psychiatry. 2015;20(4):44753. https://doi.org/10.1038/mp.2014.74.

172. Aoki Y, Yahata N, Watanabe T, Takano Y, Kawakubo Y, Kuwabara $\mathrm{H}$, et al. Oxytocin improves behavioural and neural deficits in inferring others' social emotions in autism. Brain. 2014;137(Pt 11):3073-86. https://doi.org/10.1093/brain/awu231.

173. Sauer C, Montag C, Worner C, Kirsch P, Reuter M. Effects of a common variant in the $\mathrm{CD} 38$ gene on social processing in an oxytocin challenge study: possible links to autism. Neuropsychopharmacology. 2012;37(6):1474-82. https://doi.org/10.1038/ npp.2011.333.

174. Althaus M, Groen Y, Wijers A, Noltes H, Tucha O, Sweep FC, et al. Do blood plasma levels of oxytocin moderate the effect of nasally administered oxytocin on social orienting in highfunctioning male adults with autism spectrum disorder? Psychopharmacology (Berl). 2016;233(14):2737-51. https://doi. org/10.1007/s00213-016-4339-1.

175. Althaus M, Groen Y, Wijers AA, Noltes H, Tucha O, Hoekstra PJ. Oxytocin enhances orienting to social information in a selective group of high-functioning male adults with autism spectrum disorder. Neuropsychologia. 2015;79(Pt A):53-69. https://doi. org/10.1016/j.neuropsychologia.2015.10.025.

176. Guastella AJ, Hickie IB, McGuinness MM, Otis M, Woods EA, Disinger HM, et al. Recommendations for the standardisation of oxytocin nasal administration and guidelines for its reporting in human research. Psychoneuroendocrinology. 2013;38(5):612-25. https://doi.org/10.1016/j.psyneuen.2012.11.019.

177. Gossen A, Hahn A, Westphal L, Prinz S, Schultz RT, Grunder $\mathrm{G}$, et al. Oxytocin plasma concentrations after single intranasal oxytocin administration: a study in healthy men. Neuropeptides. 2012;46(5):211-5. https://doi.org/10.1016/j.npep.2012.07.001.

178. Kirkpatrick MG, Francis SM, Lee R, de Wit H, Jacob S. Plasma oxytocin concentrations following MDMA or intranasal oxytocin in humans. Psychoneuroendocrinology. 2014;46:23-31. https:// doi.org/10.1016/j.psyneuen.2014.04.006.

179. Freeman SM, Samineni S, Allen PC, Stockinger D, Bales KL, Hwa GG, et al. Plasma and CSF oxytocin levels after intranasal and intravenous oxytocin in awake macaques. Psychoneuroendocrinology. 2016;66:185-94. https://doi.org/10.1016/j.psyne uen.2016.01.014.

180. Tanaka A, Furubayashi T, Arai M, Inoue D, Kimura S, Kiriyama A, et al. Delivery of oxytocin to the brain for the treatment of autism spectrum disorder by nasal application. Mol Pharm. 2018;15(3):1105-11. https://doi.org/10.1021/acs.molpharmac eut.7b00991.

181. Cataldo I, Azhari A, Esposito G. A review of oxytocin and arginine-vasopressin receptors and their modulation of autism spectrum disorder. Front Mol Neurosci. 2018;11:27. https://doi. org/10.3389/fnmol.2018.00027.

182. Zink CF, Stein JL, Kempf L, Hakimi S, Meyer-Lindenberg A. Vasopressin modulates medial prefrontal cortex-amygdala circuitry during emotion processing in humans. J Neurosci. 2010;30(20):7017-22. https://doi.org/10.1523/JNEUR OSCI.4899-09.2010.

183. Zink CF, Kempf L, Hakimi S, Rainey CA, Stein JL, Meyer-Lindenberg A. Vasopressin modulates social recognition-related activity in the left temporoparietal junction in humans. Transl Psychiatry. 2011;1:e3. https://doi.org/10.1038/tp.2011.2.

184. Caldwell HK, Aulino EA, Rodriguez KM, Witchey SK, Yaw AM. Social context, stress, neuropsychiatric disorders, and the vasopressin 1b receptor. Front Neurosci. 2017;11:567. https:// doi.org/10.3389/fnins.2017.00567.

185. Umbricht D, Del Valle Rubido M, Hollander E, McCracken JT, Shic F, Scahill L, et al. A single dose, randomized, controlled proof-of-mechanism study of a novel vasopressin 1a receptor antagonist (RG7713) in high-functioning adults with autism spectrum disorder. Neuropsychopharmacology. 2017;42(9):1914-23. https://doi.org/10.1038/npp.2016.232.

186. Bolognani F, del Valle Rubido M, Squassante L, Wandel C, Liogier D'ardhuy X, Boak L, et al., editors. Results of a phase 2 
randomized double-blind placebo controlled study (VANILLA) investigating the efficacy and safety of a V1a antagonist (RG7314) in adult men with ASD. San Francisco: IMFAR; 2017.

187. Parker KJ, Oztan O, Libove RA, Sumiyoshi RD, Karhson DS, Summers J, et al., editors. Intranasal vasopressin treatment improves social abilities in children with autism. San Francisco: IMFAR; 2017.

188. Ramaekers VT, Sequeira JM, Blau N, Quadros EV. A milk-free diet downregulates folate receptor autoimmunity in cerebral folate deficiency syndrome. Dev Med Child Neurol. 2008;50(5):34652. https://doi.org/10.1111/j.1469-8749.2008.02053.x.

189. Moretti P, Sahoo T, Hyland K, Bottiglieri T, Peters S, del Gaudio D, et al. Cerebral folate deficiency with developmental delay, autism, and response to folinic acid. Neurology. 2005;64(6):1088-90. https://doi.org/10.1212/01.WNL.00001 54641.08211.B7.

190. Moretti P, Peters SU, Del Gaudio D, Sahoo T, Hyland K, Bottiglieri T, et al. Brief report: autistic symptoms, developmental regression, mental retardation, epilepsy, and dyskinesias in CNS folate deficiency. J Autism Dev Disord. 2008;38(6):1170-7. https ://doi.org/10.1007/s10803-007-0492-z.

191. Ramaekers VT, Rothenberg SP, Sequeira JM, Opladen T, Blau N, Quadros EV, et al. Autoantibodies to folate receptors in the cerebral folate deficiency syndrome. N Engl J Med. 2005;352(19):1985-91. https://doi.org/10.1056/NEJMoa043160.

192. Ramaekers VT, Blau N, Sequeira JM, Nassogne MC, Quadros EV. Folate receptor autoimmunity and cerebral folate deficiency in low-functioning autism with neurological deficits. Neuropediatrics. 2007;38(6):276-81. https://doi.org/10.1055/s-2008-10653 54.

193. Frye RE, Melnyk S, Fuchs G, Reid T, Jernigan S, Pavliv O, et al. Effectiveness of methylcobalamin and folinic Acid treatment on adaptive behavior in children with autistic disorder is related to glutathione redox status. Autism Res Treat. 2013;2013:609705. https://doi.org/10.1155/2013/609705.

194. Hendren RL, James SJ, Widjaja F, Lawton B, Rosenblatt A, Bent S. Randomized, placebo-controlled trial of methyl $\mathrm{B}_{12}$ for children with autism. J Child Adolesc Psychopharmacol. 2016;26(9):774-83. https://doi.org/10.1089/cap.2015.0159.

195. Schmaal L, Veltman DJ, Nederveen A, van den Brink W, Goudriaan AE. N-acetylcysteine normalizes glutamate levels in cocaine-dependent patients: a randomized crossover magnetic resonance spectroscopy study. Neuropsychopharmacology. 2012;37(9):2143-52. https://doi.org/10.1038/npp.2012.66.

196. Hardan AY, Fung LK, Libove RA, Obukhanych TV, Nair S, Herzenberg LA, et al. A randomized controlled pilot trial of oral $N$-acetylcysteine in children with autism. Biol Psychiatry. 2012;71(11):956-61. https://doi.org/10.1016/j.biops ych.2012.01.014

197. Ghanizadeh A, Derakhshan N. N-acetylcysteine for treatment of autism, a case report. J Res Med Sci. 2012;17(10):985-7.

198. Nikoo M, Radnia H, Farokhnia M, Mohammadi MR, Akhondzadeh $\mathrm{S}$. $\mathrm{N}$-acetylcysteine as an adjunctive therapy to risperidone for treatment of irritability in autism: a randomized, doubleblind, placebo-controlled clinical trial of efficacy and safety. Clin Neuropharmacol. 2015;38(1):11-7. https://doi.org/10.1097/ WNF.0000000000000063.

199. Dean OM, Gray KM, Villagonzalo KA, Dodd S, Mohebbi M, Vick T, et al. A randomised, double blind, placebo-controlled trial of a fixed dose of $N$-acetyl cysteine in children with autistic disorder. Aust N Z J Psychiatry. 2017;51(3):241-9. https://doi. org/10.1177/0004867416652735.

200. Wink LK, Adams R, Wang Z, Klaunig JE, Plawecki MH, Posey DJ, et al. A randomized placebo-controlled pilot study of $N$-acetylcysteine in youth with autism spectrum disorder. Mol Autism. 2016;7:26. https://doi.org/10.1186/s13229-016-0088-6.
201. Danfors T, von Knorring AL, Hartvig P, Langstrom B, Moulder $\mathrm{R}$, Stromberg B, et al. Tetrahydrobiopterin in the treatment of children with autistic disorder: a double-blind placebo-controlled crossover study. J Clin Psychopharmacol. 2005;25(5):485-9.

202. Klaiman C, Huffman L, Masaki L, Elliott GR. Tetrahydrobiopterin as a treatment for autism spectrum disorders: a doubleblind, placebo-controlled trial. J Child Adolesc Psychopharmacol. 2013;23(5):320-8. https://doi.org/10.1089/cap.2012.0127.

203. Nareuse H, Hayash TI, Takesada M, Nakane A, Yamazaki K, Noguchi T, et al. Therapeutic effect of tetrahydrobiopterin in infantile autism. Proc Jpn Acad. 1987;1987:231-3.

204. Geier DA, Kern JK, Davis G, King PG, Adams JB, Young JL, et al. A prospective double-blind, randomized clinical trial of levocarnitine to treat autism spectrum disorders. Med Sci Monit. 2011;17(6):PI15-23.

205. Fahmy SF, El-hamamsy MH, Zaki OK, Badary OA. 1-Carnitine supplementation improves the behavioral symptoms in autistic children. Res Autism Spectr Disord. 2013;7(1):159-66.

206. Bent S, Lawton B, Warren T, Widjaja F, Dang K, Fahey JW, et al. Identification of urinary metabolites that correlate with clinical improvements in children with autism treated with sulforaphane from broccoli. Mol Autism. 2018;9:35. https://doi.org/10.1186/ s13229-018-0218-4.

207. Frye RE, Slattery J, MacFabe DF, Allen-Vercoe E, Parker W, Rodakis $\mathrm{J}$, et al. Approaches to studying and manipulating the enteric microbiome to improve autism symptoms. Microb Ecol Health Dis. 2015;26:26878. https://doi.org/10.3402/mehd. v26.26878.

208. Parracho H, Gibson GR, Knott F, Bosscher D, Kleerebezem M, McCartney AL. A double-blind, placebo-controlled, crossover-designed probiotic feeding study in children diagnosed with autistic spectrum disorders. Int J Probiotics Prebiotics. 2010;5(2):69-74.

209. West R, Roberts E, Sichel LS, Sichel J. Improvements in gastrointestinal symptoms among children with autism spectrum disorder receiving the Delpro ${ }^{\circledR}$ probiotic and immunomodulator formulation. J Probiotics Health. 2013;1(102):2.

210. Kang DW, Adams JB, Gregory AC, Borody T, Chittick L, Fasano A, et al. Microbiota transfer therapy alters gut ecosystem and improves gastrointestinal and autism symptoms: an open-label study. Microbiome. 2017;5(1):10. https://doi.org/10.1186/s4016 8-016-0225-7.

211. Frye RE, Rose S, Chacko J, Wynne R, Bennuri SC, Slattery $\mathrm{JC}$, et al. Modulation of mitochondrial function by the microbiome metabolite propionic acid in autism and control cell lines. Transl Psychiatry. 2016;6(10):e927. https://doi.org/10.1038/ tp.2016.189.

212. Rose S, Bennuri SC, Davis JE, Wynne R, Slattery JC, Tippett M, et al. Butyrate enhances mitochondrial function during oxidative stress in cell lines from boys with autism. Transl Psychiatry. 2018;8(1):42. https://doi.org/10.1038/s41398-017-0089-z.

213. Frye RE, Melnyk S, Macfabe DF. Unique acyl-carnitine profiles are potential biomarkers for acquired mitochondrial disease in autism spectrum disorder. Transl Psychiatry. 2013;3:e220. https ://doi.org/10.1038/tp.2012.143.

214. Takuma K, Hara Y, Kataoka S, Kawanai T, Maeda Y, Watanabe $\mathrm{R}$, et al. Chronic treatment with valproic acid or sodium butyrate attenuates novel object recognition deficits and hippocampal dendritic spine loss in a mouse model of autism. Pharmacol Biochem Behav. 2014;126:43-9. https://doi.org/10.1016/j. pbb.2014.08.013.

215. Kratsman N, Getselter D, Elliott E. Sodium butyrate attenuates social behavior deficits and modifies the transcription of inhibitory/excitatory genes in the frontal cortex of an autism model. Neuropharmacology. 2016;102:136-45. https://doi. org/10.1016/j.neuropharm.2015.11.003. 
216. Chadman KK. Animal models for autism in 2017 and the consequential implications to drug discovery. Expert Opin Drug Discov. 2017;12(12):1187-94. https://doi.org/10.1080/17460 441.2017.1383982.

217. Beversdorf DQ. Phenotyping, etiological factors, and biomarkers: toward precision medicine in autism spectrum disorders. J Dev Behav Pediatr. 2016;37(8):659-73. https://doi.org/10.1097/ dbp.0000000000000351.
218. King BH, Dukes K, Donnelly CL, Sikich L, McCracken JT, Scahill L, et al. Baseline factors predicting placebo response to treatment in children and adolescents with autism spectrum disorders: a multisite randomized clinical trial. JAMA Pediatr. 2013;167(11):1045-52. https://doi.org/10.1001/jamapediat rics.2013.2698. 